63. Jin, P et al Novel splice variants derived from the receptor tyrosine kinase superfamily are potential therapeutics for rheumatoid arthritis. Arthritis Res. Ther. 10, R73 (2008).

64. Gagnon, M. L. et al. Identification of a natural soluble neuropilin-1 that binds vascular endothelial growth factor: In vivo expression and antitumor activity. Proc. Natl Acad. Sci. USA 97, 2573-2578 (2000).

65. Saarela, J., Ylikarppa, R., Rehn, M., Purmonen, S. \& Pihlajaniemi, T. Complete primary structure of two variant forms of human type XVIII collagen and tissuespecific differences in the expression of the corresponding transcripts. Matrix Biol. 16, 319-328 (1998).

66. Mundel, T. M. \& Kalluri, R. Type IV collagen-derived angiogenesis inhibitors. Microvasc Res 74 85-89 (2007).

67. Bates, D. O. \& Harper, S. J. Therapeutic potential of inhibitory VEGF splice variants. Fut. Oncol. 1 , 467-473 (2005)

68. Jin, W. \& Cote, G.J. Enhancer-dependent splicing of FGFR $1 \alpha$-exon is repressed by RNA interferencemediated down-regulation of SRp55. Cancer Res. 64 8901-8905 (2004).

69 Folkman, J. Anti-angiogenesis: new concept for therapy of solid tumors. Ann. Surg. 175, 409-416 (1972).

70. Pugh, C. W. \& Ratcliffe, P. J. Regulation of angiogenesis by hypoxia: role of the HIF system. Nature Med. 9, 677-684 (2003).

71. Whittle, C., Gillespie, K., Harrison, R., Mathieson, P. W. $\&$ Harper, S. J. Heterogeneous vascular endothelial growth factor (VEGF) isoform mRNA and receptor mRNA expression in human glomeruli, and the identification of VEGF148 mRNA, a novel truncated splice variant. Clin. Sci. (Lond.) 97, 303-312 (1999).

72. Hirose, Y., Tacke, R. \& Manley, J. L. Phosphorylated RNA polymerase II stimulates pre-mRNA splicing. Genes Dev. 13, 1234-1239 (1999).

73. Koenigsberger, C., Chicca, J. J. 2nd, Amoureux, M. C. Edelman, G. M. \& Jones, F. S. Differential regulation by multiple promoters of the gene encoding the neuron-restrictive silencer factor. Proc. Natl Acad. Sci. USA 97, 2291-2296 (2000).

74 Starovasnik, M. A. et al. Solution structure of the VEGF-binding domain of FIt-1: comparison of its free and bound states. J. Mol. Biol. 293, 531-544 (1999)

75. Muller, Y. A., Christinger, H. W., Keyt, B. A. \& de Vos, A. M. The crystal structure of vascular endothelial growth factor (VEGF) refined to $1.93 \AA$ resolution: multiple copy flexibility and receptor binding. Structure 5, 1325-1338 (1997).

76. Fairbrother, W. J., Champe, M. A., Christinger, H. W., Keyt, B. A. \& Starovasnik, M. A. Solution structure of the heparin-binding domain of vascular endothelial growth factor. Structure 6, 637-648 (1998).

77. Keck, R. G., Berleau, L., Harris, R. \& Keyt, B. A. Disulfide structure of the heparin binding domain in vascular endothelial growth factor: characterization of posttranslational modifications in VEGF. Arch. Biochem. Biophys. 344, 103-113 (1997).

78. Claffey, K. P., Senger, D. R. \& Spiegelman, B. M. Structural requirements for dimerization, glycosylation, secretion, and biological function of VPF/VEGF. Biochim. Biophys. Acta Prot. Struct. Mol. Enzymol. 1246, 1-9 (1995).

Competing interests statement

The authors declare competing financial interests: see web version for details.

\section{DATABASES}

National Cancer Institute: http://www.cancer.gov/

bladder cancer | colorectal carcinoma $\mid$ Ewing sarcoma

kidney cancer / melanoma | prostate cancer

National Cancer Institute Drug Dictionary: http://www.

cancer.gov/drugdictionary/

aflibercept | bevacizumab | sorafenib | sunitinib

UniProtKB: http://www.uniprot.org

- -globin | collagen IV | collagen XVII| FGFR1 |FGFR2 |FGFR4

fibronectin | nephrin | neuropilin 1 |PDGFR $\mid$ | placenta

growth factor |SRP55 |VEGFA |VEGFR1|VEGFR2 |VEGFR3

FURTHER INFORMATION

S. J. Harper's homepage: http://www.mvrl.org

ALL LINKS ARE ACTIVE IN THE ONLINE PDF

OPINION

\title{
Cytokines and their relationship to the symptoms and outcome of cancer
}

\section{Bostjan Seruga, Haibo Zhang, Lori J. Bernstein and Ian F. Tannock}

Abstract | Tumours contain immune cells and a network of pro- and antiinflammatory cytokines, which collaborate in the development and progression of cancer. Cytokine profiles might prove to be prognostic. The systemic effects of pro-inflammatory cytokines are associated with fatigue, depression and cognitive impairment, and can affect quality of life before, during and after treatment. In people with advanced cancer, pro-inflammatory cytokines are additionally associated with anorexia and cachexia, pain, toxicity of treatment and resistance to treatment. However, physical activity might modify cytokine levels and decrease fatigue in patients with cancer, and might also improve their prognosis.

Cytokines are a heterogeneous group of soluble small polypeptides or glycoproteins, which exert pleiotropic and redundant effects that promote growth, differentiation and activation of normal cells ${ }^{1}$. Cytokines can have either pro- or anti-inflammatory activity and immunosuppressive activity, depending on the microenvironment. Immune cells are the major source of cytokines but many human cells are capable of producing them ${ }^{1,2}$ (TABLE 1) and, importantly, their production acts as a means of communication between both cells and tissues.

In this Perspective we discuss the role of cytokines in causing symptoms that affect quality of life in people with cancer and the possible influence of cytokines on cancer outcome.

\section{Cytokines and cancer development}

Under normal conditions, an inflammatory response $(\mathrm{BOX} 1)$ is regulated by active mechanisms. Anti-inflammatory cytokines, such as interleukin 10 (IL10) and transforming growth factor $\beta$ (TGF $\beta$ ), are important in this process, as are soluble receptors that neutralize the activity of cytokines, such as soluble IL1 receptor type II (IL1R2), and cytokine receptor antagonists, such as IL1RA. Although often overlooked, neuronal pathways and hormones (such as cortisol and adrenaline) $)^{3,4}$ also affect the immune response. Adrenal production of cortisol, a potent anti-inflammatory glucocorticoid hormone, is regulated by the hypothalamic-pituitary-adrenal (HPA) axis $^{5}$. Disrupted HPA signalling resulting in altered release of glucocorticoid hormones, or disrupted glucocorticoid receptor function, might sustain inflammation. A disturbed balance between pro- and antiinflammatory mechanisms leads to chronic immune activation and inflammation ${ }^{6}$, as occurs often in people with cancer.

Clinical studies. Clinical and epidemiological studies have suggested a strong association between chronic local inflammation and some types of cancer ${ }^{7}$, with inflammation often occurring in and around tumours 8 . Prehn first reported in 1972 that immune cells promote tumour growth in an animal model ${ }^{9}$, and it is now established that the tumour stroma includes inflammatory cells, such as M2 macrophages, dendritic cells and T-regulatory lymphocytes ${ }^{10}$ (BOX 1), that promote development and progression of cancer ${ }^{10-12}$ (FIG. 1).

The tumour microenvironment is rich in cytokines and other inflammatory mediators that influence immunosuppression, growth of cancer cells, tissue remodelling and angiogenesis $^{13-15}$ (FIG. 1). Immunosuppressive networks mediated by IL10 and TGF $\beta$ seem to inhibit cell-mediated immune responses against cancer cells ${ }^{16}$. Moreover, the function of circulating $\mathrm{T}$ cells is often impaired in cancer ${ }^{17}$. Clinical data show a decreased ratio of circulating Thelper $1\left(\mathrm{~T}_{\mathrm{H}} 1\right)$ cells to circulating $\mathrm{T}_{\mathrm{H}} 2$ cells and their associated cytokines in different cancer types and in 


\section{Table 1 | Cytokines, immunity and inflammation}

\begin{tabular}{|c|c|}
\hline Activity & Cytokines and receptors \\
\hline $\begin{array}{l}\text { Cell-mediated immunity } \\
\text { (pro-inflammatory) }\end{array}$ & $\begin{array}{l}\text { IL1, IL2, IL4, IL6, IL7, IL10, IL11, IL12 IL15, IL16, IL17, IL18, IL21, IL23, } \\
\text { TNF } \alpha \text {, TNF } \beta \text {, IFN } \alpha \text {, IFN } \beta \text {, IFN } \gamma\end{array}$ \\
\hline $\begin{array}{l}\text { Humoral immunity } \\
\text { (pro-inflammatory) }\end{array}$ & IL1, IL2, IL4, IL5, IL6, IL10, IL12, IL13, IL15, IL21, IL25, TGF $\beta$ \\
\hline $\begin{array}{l}\text { Allergic immunity } \\
\text { (pro-inflammatory) }\end{array}$ & IL3, IL4, IL5, IL9, IL13, IL25, IFN \\
\hline Anti-inflammatory & $\begin{array}{l}\text { IL4, IL5, IL6, IL10, IL13, IL19, IL20, IL22, IL24, IL26, TGF } \beta \text {, IL1RA, } \\
\text { signalling by IL1RII }\end{array}$ \\
\hline \multicolumn{2}{|c|}{$\begin{array}{l}\text { Pro-inflammatory cytokines stimulate cell-mediated, humoral and/or allergic immunity. The major } \\
\text { cytokine mediating cell-mediated immunity is interferon- } \gamma \text { (IFN } \gamma \text { ). Humoral immunity is mediated by B cells } \\
\text { and production of antibodies; interleukin } 4 \text { (IL4), IL10, IL13 and transforming growth factor- } \beta \text { (TGF }) \\
\text { trigger isotype switching of antibodies. Some cytokines have predominantly anti-inflammatory and } \\
\text { immunosuppressive effects (for example, IL10 and TGF } \beta \text { ) or both pro- and anti-inflammatory effects (for } \\
\text { example, IL6). Innate immune cells are the major source of IL1, IL6 and tumour necrosis factor- } \alpha \text { (TNF } \alpha \text { ), } \\
\text { which direct activity of adaptive immunity and inflammation. GM-CSF, granulocyte macrophage-colony } \\
\text { stimulating factor; IL1RA, IL1 receptor antagonist; IL1RII, IL1 receptor type II; TNF, tumour necrosis factor; } \\
\text { SCF, stem cell factor. }\end{array}$} \\
\hline
\end{tabular}

chronic inflammatory conditions that are associated with an increased risk of cancer ${ }^{18}$. This decrease in the level of $\mathrm{T}_{\mathrm{H}} 1$ cells restricts the cell-mediated pro-inflammatory response.

Increased levels of circulating cytokines and their receptors (most often of the proinflammatory cytokine IL6) have been found in observational studies of patients with various types of cancer, both at diagnosis of the primary disease and in those with metastases, compared with healthy people and people with benign tumours ${ }^{19-28}$ (TABLE 2). There have been few studies of circulating levels of cytokines in people after primary treatment of cancer and in cancer survivors. In a longitudinal study of patients with kidney cancer, circulating levels of IL6 and IL10 at diagnosis were higher than in controls with benign kidney disease, and remained significantly higher 3 months after resection of the primary tumour ${ }^{25}$. Preliminary data from our group ${ }^{29}$ indicate that circulating levels of several different pro- and anti-inflammatory cytokines are substantially higher in people without active breast or colorectal cancer up to 5 years after diagnosis than in healthy controls.

Polymorphisms. Human genetic variation can modulate the risk of developing a cancer, the risk of developing symptoms related to cancer and its treatment, and the outcome of cancer. The most common variations in the genome are single-nucleotide polymorphisms (SNPs) ${ }^{30}$. In human disease several SNPs in genes encoding cytokines have been associated with variations in the level of transcription and expression, but for many cytokines the data are inconsistent (see Cytokine gene polymorphism in human disease in Further information). In a systematic review of 161 meta-analyses and pooled analyses of SNPs in 99 candidate genes in 18 cancer sites, nearly one-third (98/344) of gene variants were significantly associated with cancer, including 6 cytokine gene variants ${ }^{31}$. Other small studies indicate that SNPs in cytokine genes might be involved in the development of cancer $^{32-39}$ (TABLE 3); however, such results are not always in agreement ${ }^{40,41}$. Generally, candidate gene studies are considered to be informative but to have limitations, a lack of replication being the main concern in these relatively small studies ${ }^{42}$.

\section{Cytokines and the central nervous system} Macrophages in the brain, known as microglial cells, are an important source of proinflammatory cytokines, and are involved in the pathogenesis of various neurological diseases ${ }^{43}$. Furthermore, inflammatory stimuli, including circulating cytokines, can reach the brain by several pathways ${ }^{44-50}$ (FIG. 2) and stimulate microglial cells to produce pro-inflammatory cytokines and other inflammatory mediators. The best example of the communication between peripheral cytokines and the brain is 'sickness behaviour', which is induced by peripheral infection and mediated by temporarily expressed pro-inflammatory cytokines in the periphery and in the brain ${ }^{51}$. Similarly, peripherally produced cytokines in cancer may have a role in the development of psychobehavioural symptoms, such as fatigue and cognitive impairment.

Cytokines and symptoms in cancer patients Cytokines and cancer treatment. The production and release of cytokines can be effected by the cancer itself and by different treatments. Some cytokines, including interferon $\alpha$ (IFN $\alpha$ ) and IL2, have been used in cancer treatment, and their ability to cause fatigue, depression and other symptoms is well-described $^{52-54}$. Release of cytokines may mediate both the organ-confined and the systemic toxic symptoms that are associated with different types of cancer treatment such as radiation therapy, chemotherapy and hormonal therapy (FIG. 3).

Radiation therapy can lead to release of cytokines in various tissues, and cytokines are associated with the development of late radiation damage that can occur in irradiated normal tissues months or years after treatment ${ }^{55}$. TGF $\beta$ has a crucial role in the initiation, development and persistence of radiation-induced fibrosis ${ }^{56}$, and circulating levels of TGF $\beta 1$ predict radiation-induced lung damage ${ }^{57}$. The TGF $\beta 1(-509 \mathrm{~T})$ allele is associated with increased circulating levels of TGF $\beta 1$ (REF. 58) and radiation-induced damage in normal tissues in women with early breast cancer ${ }^{59-61}$ or gynaecological cancers $^{62}$. Combined analysis of two studies of women with breast cancer showed that the $8 \%$ of patients who were homozygous for the TGF $\beta 1(-509 \mathrm{~T})$ variant allele had a 15 -fold increase in risk of fibrosis following radiotherapy ${ }^{61}$ (TABLE 3). Cytokines might also have systemic effects after radiation treatment. Evidence from animal models suggests that local irradiation of a tumour can result in regression of distant nonirradiated tumours, an effect that is mediated by $\mathrm{T}$ cells ${ }^{63}$ following systemic activation of the immune system ${ }^{64}$.

Chemotherapy is also known to have direct and indirect effects on the immune system. Chemotherapy-induced death of cancer cells can cause the release of immunogenic antigens, which result in a cell-mediated immune response to the tumour, as recently reviewed ${ }^{65}$ by Zitvogel et al. Cytokine secretion induced by chemotherapeutic drugs might also mediate the development of other side effects, including psychobehavioural effects, during and after treatment (FIG. 3). Paclitaxel can mimic the effects of lipopolysaccharide (LPS), which is a ligand for Toll-like receptor 4 (TLR4) expressed on innate immune cells. Exposure of murine macrophages to paclitaxel led to the increased release of both tumour necrosis factor $\alpha$ (TNF $\alpha$ ) and IL1 $\beta^{66-68}$. Furthermore, paclitaxel can induce expression of the pro-inflammatory cytokine IL8 in lung carcinoma cell lines ${ }^{69}$. Treatment with paclitaxel or docetaxel was reported to increase the expression of IL2, 
IL6, IFN $\gamma$ and granulocyte macrophagecolony stimulating factor (GM-CSF) and decrease the expression of IL1 and TNF $\alpha$ in women with advanced breast cancer who responded to treatment ${ }^{70}$. Adjuvant and neo-adjuvant treatment of women with breast cancer with paclitaxel also increased serum levels of IL6, IL8 and IL10, and these changes correlated with joint pain and flulike symptoms ${ }^{71}$. Another anticancer drug, etoposide, has been reported to stimulate production of IL6 by murine macrophages and to induce sickness-like behaviour in animals ${ }^{72}$. Some drugs may increase production of cytokines by the expansion of the particular pool of immune cells, which is also involved in anticancer mechanisms. For example, treatment with gemcitabine increased the numbers of IFN $\gamma$-producing T cells and activated CD69 ${ }^{+}$cells in patients with pancreatic cancer ${ }^{73}$. Chemotherapy may also cause organ-confined toxic effects, which are drug-specific and mediated by cytokines. For example, animal models support a role of increased secretion of TNF $\alpha$ in cisplatin-induced nephrotoxicity ${ }^{74,75}$. Local production of TNF $\alpha$ by renal parenchymal cells promotes damage and is associated with increased circulating and urinary levels of $\mathrm{TNF}^{76}$. Bleomycin has a major role in treatment of testicular tumours and Hodgkin lymphoma but is associated with pulmonary toxicity and occasionally with fatal pulmonary fibrosis ${ }^{77}$. In animal models of bleomycin-induced lung fibrosis, TGF $\beta 1$ is a pivotal pro-fibrotic cytokine and other pro-inflammatory cytokines (such as IL1, IL6 and TNF $\alpha$ ) also contribute $\mathrm{e}^{78-80}$.

Aromatase inhibitors, which reduce oestrogen to low levels in the plasma and tissues of postmenopausal women ${ }^{81}$, are used frequently as adjuvant hormonal treatment in postmenopausal women with breast cancer but can cause arthralgia (joint pain) and bone loss, sometimes leading to discontinuation of treatment. In premenopausal women, treatment of cancer can induce premature ovarian failure and significant decreases in oestrogen levels ${ }^{82}$. Various immune cells (such as dendritic cells, macrophages and B cells) express oestrogen receptors and oestrogen can influence their activity ${ }^{83}$. Oestrogen downregulates cellmediated immune responses and promotes humoral immune responses, whereas oestrogen deficiency increases cell-mediated immune responses and the production of pro-inflammatory cytokines such as IL1, IL6 and $\mathrm{TNF}^{84}$. These cytokines might mediate arthralgia during therapy with aromatase inhibitors. Animal models have shown that

\section{Box 1 | Role of cytokines in inflammation and immune responses}

Innate immunity is a non-specific, short-lasting first line of host defence that depends on cells of myeloid (for example, monocytes, macrophages, dendritic cells, neutrophils and mast cells) and lymphoid (for example, natural killer cells) origin ${ }^{229}$. Various innate and other immune cells express germline-encoded receptors, including Toll-like receptors (TLRs); these receptors recognize a range of exogenous microbial antigens and endogenous ligands, which include nucleic acids and heat shock proteins. When activated, TLRs lead to activation of nuclear factor $\kappa B$ and cytokine production, which mediates the nature and magnitude of adaptive inflammatory responses ${ }^{230-232}$. Cancer cells can acquire properties characteristic of innate immune cells; they not only produce cytokines but can also express functional TLRs ${ }^{233-235}$.

During an innate immune response macrophages are activated and form a continuum between M1 and $\mathrm{M} 2$ macrophages, which produce different cytokines and receptors for cytokines. M1 macrophages stimulate cell-mediated responses through the production of pro-inflammatory cytokines (interleukin 1 (IL1), IL6, IL12, IL23, tumour necrosis factor- $\alpha$ and high levels of signalling IL1 receptor type I (IL1RI)), whereas M2-macrophages stimulate humoral responses, tissue remodelling and angiogenesis through the production of anti-inflammatory cytokines (IL10 and transforming growth factor- $\beta$ (TGF $\beta$ )) and high levels of decoys that antagonize IL1, such as IL1RII and IL1 receptor antagonist ${ }^{236} . M 2$ macrophages are found commonly among the host cells that infiltrate most tumours ${ }^{10}$.

Cells of the adaptive immune system are activated later and induce a long-lasting and specific immune response mediated by $C D 4^{+} T$-helper $\left(T_{H}\right)$ cells, cytotoxic $C D 8^{+} T$ cells and $B$ cells ${ }^{237}$.

Complicated cascades of cytokines produced after activation of the innate immune system guide differentiation of naive $C D 4^{+} T_{H} 0$ cells into effector $T_{H}$ cell subtypes: $T_{H} 1, T_{H} 2, T_{H} 17$ and T-regulatory cells ${ }^{238}$. The functions of $\mathrm{T}_{\mathrm{H}} 1$ and $\mathrm{T}_{\mathrm{H}} 2$ cells relate to the distinctive cytokines that they produce: in general, $T_{H} 1$ cytokines support cell-mediated immune responses, including cytotoxic immunity against cancer cells, whereas $\mathrm{T}_{\mathrm{H}} 2$ cytokines support humoral, allergic and anti-inflammatory responses $s^{1,239,240}$ (TABLE 1). Other leukocytes also contribute to $\mathrm{T}_{\mathrm{H}} 1$-like or $\mathrm{T}_{\mathrm{H}} 2$-like responses ${ }^{240}$. The characteristic $\mathrm{T}_{H} 1$ cytokine (interferon- $\gamma$ ) and $\mathrm{T}_{H} 2$ cytokines (IL4 and IL10) inhibit the differentiation and function of the reciprocal phenotype. $\mathrm{T}_{\mathrm{H}} 17$ cells are responsible for the pathogenesis of many autoimmune diseases ${ }^{241}$, but their role in cancer is uncertain. T-regulatory cells suppress immune responses, induce self-tolerance by production of the anti-inflammatory and immunosuppressive cytokines IL10 and TGF $\beta$, and are commonly found in developing tumours ${ }^{242}$.

TNF $\alpha$ secreted under conditions of oestrogen deficiency directly promotes osteoclast activation and bone resorption. TNF $\alpha$ also augments the sensitivity of maturing osteoclasts to the osteoclastogenic factor RANKL (receptor activator of nuclear factor $\kappa \mathrm{B}$ (NFKB) ligand), a member of the TNF superfamily that is produced by activated T lymphocytes, bone marrow stromal cells and osteoblasts ${ }^{85}$.

Various specific cancer treatments stimulate the immune system to produce pro-inflammatory cytokines that are associated with toxic effects of treatment such as cancer-related fatigue, flu-like systemic effects and bone loss; they can lead to impaired quality of life of patients with cancer and poor compliance with treatment. However, stimulation of the immune system by specific cancer treatments might also have a substantial role in producing anticancer effects. Cancer drugs might differentially effect the secretion of cytokines in humans with cancer, and this secretion might be a tool with which to monitor the therapeutic indices of the drugs in the future.

Cytokines and fatigue, depression and cognitive impairment. Increasing evidence indicates that $30-60 \%$ of people with cancer suffer from fatigue, and that a subset of patients (especially women with breast cancer) suffer from cognitive impairment during and after treatment ${ }^{86-89}$. Fatigue and cognitive decline have a negative impact on quality of life and such symptoms can persist for at least 10 years in some breast cancer survivors ${ }^{90,91}$. The underlying mechanisms remain poorly understood, making pharmacological interventions difficult. However, there is evidence that supports increased proinflammatory cytokine production as a candidate mechanism for fatigue and cognitive impairment in cancer patients.

Studies in animals have shown that peripheral activation of the immune system by a subseptic dose of LPS (FIG. 2) induced increased expression of pro-inflammatory cytokines in the brain ${ }^{92-95}$. Circulating LPS and pro-inflammatory cytokines have been shown to disrupt learning and memory in animals ${ }^{96-99}$, but peripherally administered LPS in IL6-deficient animals did not result in cognitive defects, indicating the probable importance of IL6 in the development of cognitive impairment ${ }^{100}$. IL10 counteracts the production of IL6 by microglial cells ${ }^{101}$, and IL10-deficient animals show increased production of pro-inflammatory cytokines 


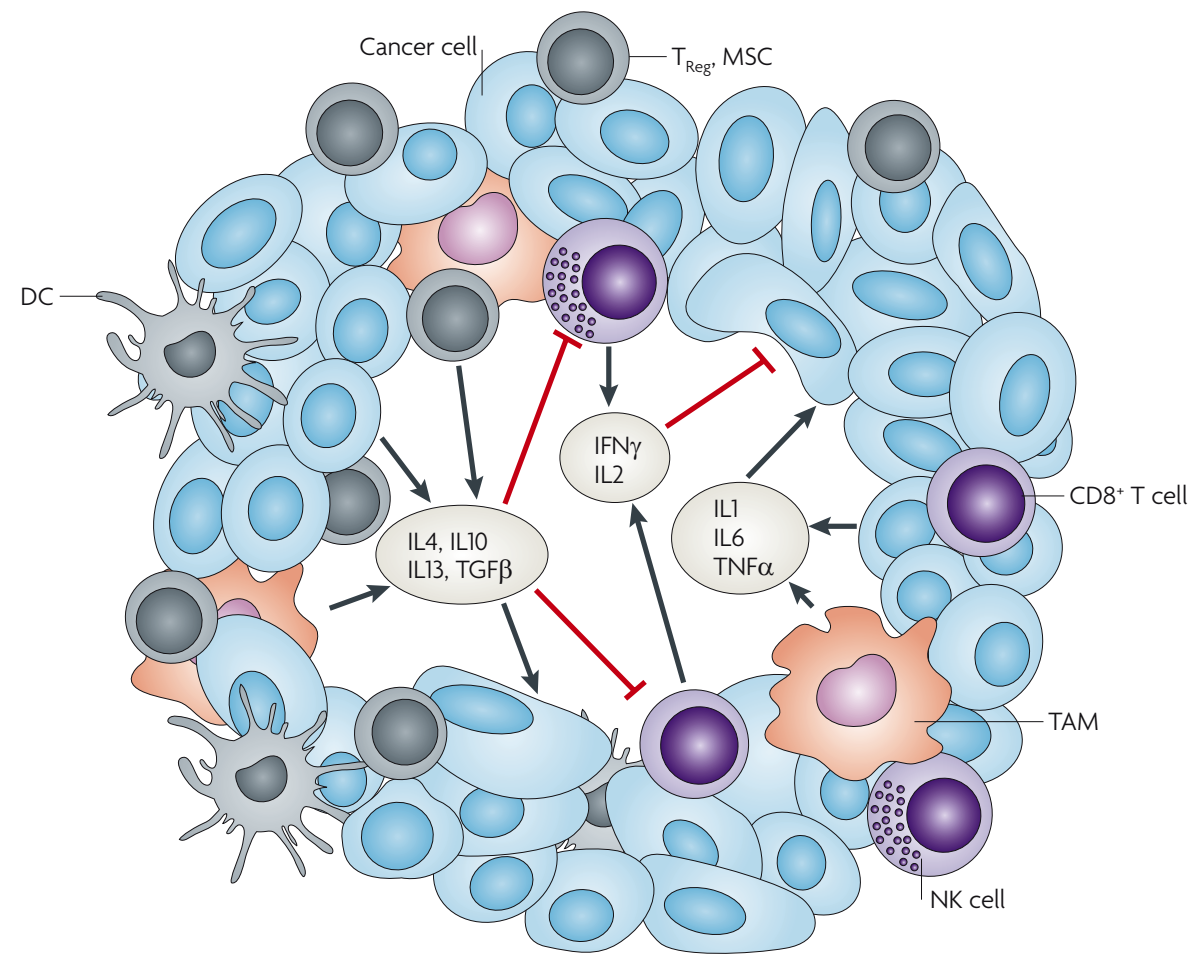

Figure 1 | Role of major cytokines in the tumour microenvironment. Cancer cells coexist with immune cells: tumour-associated macrophages (TAM), T- regulatory $\left(\mathrm{T}_{\text {Reg }}\right)$ cells, dendritic cells (DCs) and myeloid suppressor cells (MSCs). TAM and $\mathrm{T}_{\text {Reg }}$ are major sources of anti-inflammatory T-helper 2 $\left(T_{H} 2\right)$ cytokines (for example, interleukin 4 (IL4), IL10 and IL13) and transforming growth factor- $\beta$ (TGF $\beta$ ), which suppress the anticancer immunity that is mediated by natural killer (NK) cells, cytotoxic CD8 ${ }^{+}$ T cells and pro-inflammatory cytokines (for example, IL2 and interferon- $\gamma$ (IFN $\gamma$ )). Simultaneously, cancer cells directly exploit activated immune cells for their growth and development. In an immunosuppressed environment various cytokines produced by innate immune cells and cancer cells directly promote the growth of cancer cells. TNF $\alpha$, tumour necrosis factor- $\alpha$.

both in the periphery and in the brain that is associated with increased fatigue and motor deficits $^{102}$. Interestingly, increased levels of circulating IL1, TNF $\alpha$, IL6 and C-reactive protein ( $\mathrm{CRP})$ in healthy volunteers challenged by LPS were associated with impaired memory ${ }^{103}$. Increased levels of these cytokines in the elderly have been associated with gradual cognitive decline and development of dementia ${ }^{104}$. Low levels of cytokines and their receptors are produced in the central nervous system (CNS), including areas involved in memory (such as the hippocampus), and animal models have shown that physiological levels of pro-inflammatory cytokines such as IL1 are important for normal memory and neural plasticity ${ }^{105}$. Higher levels of pro-inflammatory cytokines in the brain are neurotoxic and can induce neurodegenerative disorders in humans ${ }^{106}$. In animals, administration of pro-inflammatory cytokines to the brain was found to cause increased metabolism of neurotransmitters, including noradrenaline, dopamine and serotonin ${ }^{107,108}$, which are involved in regulation of mood, memory, learning and sleep.
Increased circulating levels of cytokines are known to be associated with cancer (TABLE 2) and the pathways of communication between CNS and the periphery, including the circulatory system and the peripheral nervous system, are wellunderstood (FIG. 2). However, we have been able to identify only one published clinical study that showed an association between increased circulating levels of cytokines and cognitive impairment. In that study, patients with acute myeloid leukaemia or myelodysplastic syndrome who had higher circulating levels of IL6 at diagnosis were found to have poorer executive function, whereas higher levels of IL8 were associated with better memory ${ }^{109}$. There are no published studies demonstrating a lack of association between cytokines and cognitive impairment, but this may reflect publication bias.

In a quantitative review, a significant correlation between fatigue and circulating levels of IL6 and IL1RA was found in patients with cancer ${ }^{110}$. In breast cancer survivors, persistent fatigue has been associated with increased levels of circulating markers of inflammation including soluble $\underline{\text { IL6R }}$ and IL1RA, increased production of pro-inflammatory cytokines (IL6 and TNF $\alpha$ ) by monocytes in response to LPS at rest and in response to experimental challenge, and increased blood levels of CD4 ${ }^{+} \mathrm{T}$ cells ${ }^{111,112}$. Persistent cancer-related fatigue has also been associated with subtle deregulation of the HPA axis with flattened diurnal fluctuation of cortisol levels ${ }^{113}$ and blunted cortisol responses to experimental psychological stress ${ }^{114,115}$. Moreover, a flattened cortisol response during psychological stress was associated with increased production of IL6 by monocytes ex vivo in response to LPS stimulation ${ }^{115}$. Preliminary evidence showing that $I L 1 \beta-511 C C$ and $-511 \mathrm{CT}$ genotypes were associated with fatigue in breast cancer survivors ${ }^{116}$ (TABLE 3) suggests that the risk of development of cancer-related fatigue might be predetermined. This is further supported by the finding that flattened diurnal fluctuations in cortisol levels have been reported in some healthy individuals ${ }^{117,118}$. Decreased cortisol production rather than decreased responsiveness of the cortisol receptor appears to have a crucial role in persistent fatigue ${ }^{115}$. In a large and welldesigned prospective cohort study, psychological distress and fatigue were related to higher risk of recurrence and decreased survival in women after treatment of early breast cancer ${ }^{119}$, although this is in contrast to previous reports ${ }^{120,121}$. Some studies of patients with advanced cancer have suggested that distress and depression accelerate disease progression and decrease survival $^{122-124}$, but many studies in this field suffer from methodological limitations. In humans and animals, distress and depression are associated with impaired cellmediated immunity and decreased natural killer (NK)-cell activity ${ }^{125}$. In women with breast and ovarian cancer, high levels of psychological distress induce impairment in NK-cell activity peripherally and in the tumour ${ }^{126,127}$. The flattened diurnal fluctuations of cortisol have been associated with low peripheral NK-cell activity and with poor clinical outcome in a prospective study of women with advanced breast cancer ${ }^{128}$.

Two small clinical studies that examined the use of cytokine antagonists during cancer therapy support a causal role of proinflammatory cytokines in cancer-related fatigue. In a small randomized, controlled trial for cancer patients receiving weekly docetaxel (which is known to induce 


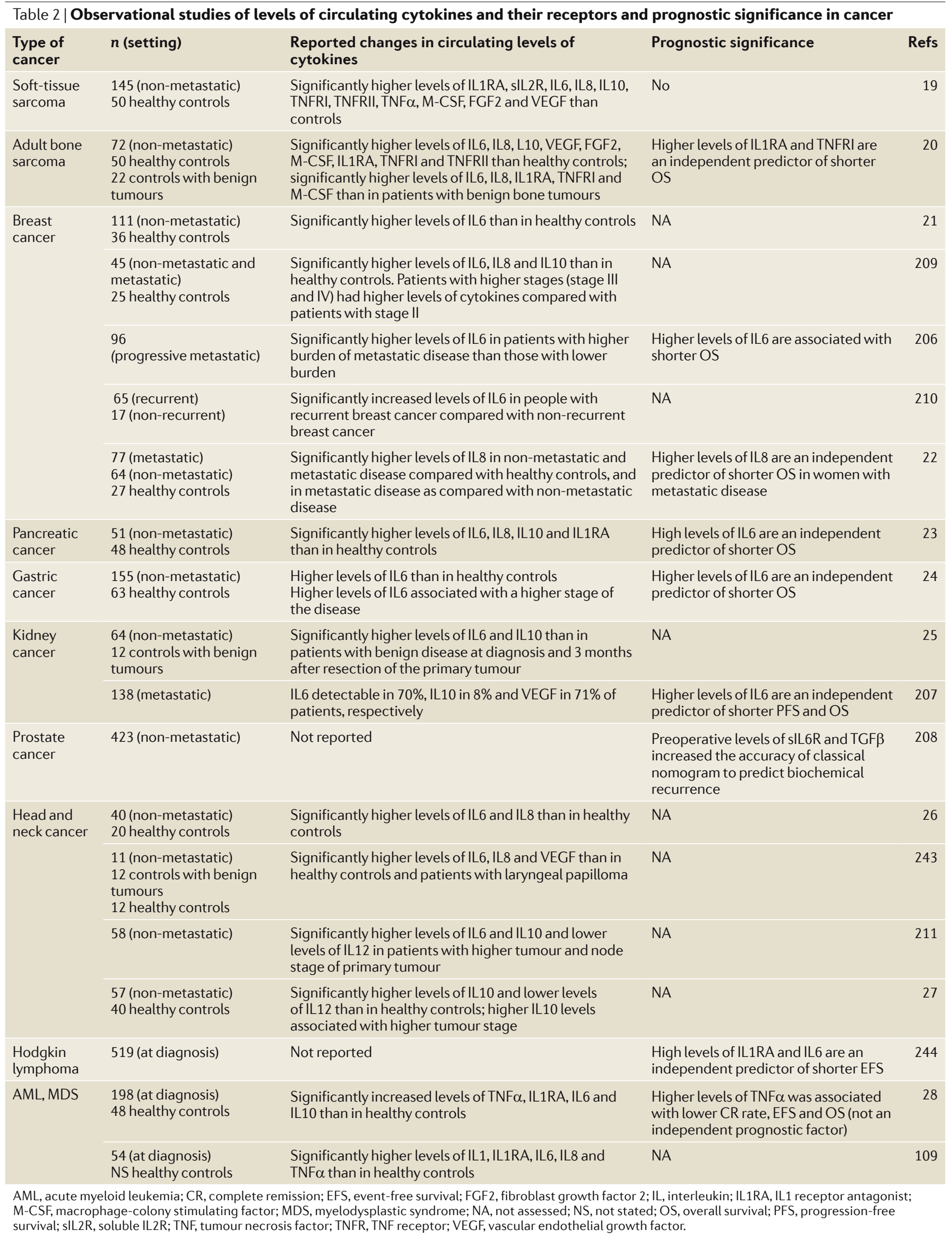


Table 3 | Genetic polymorphisms of cytokine genes associated with cancer

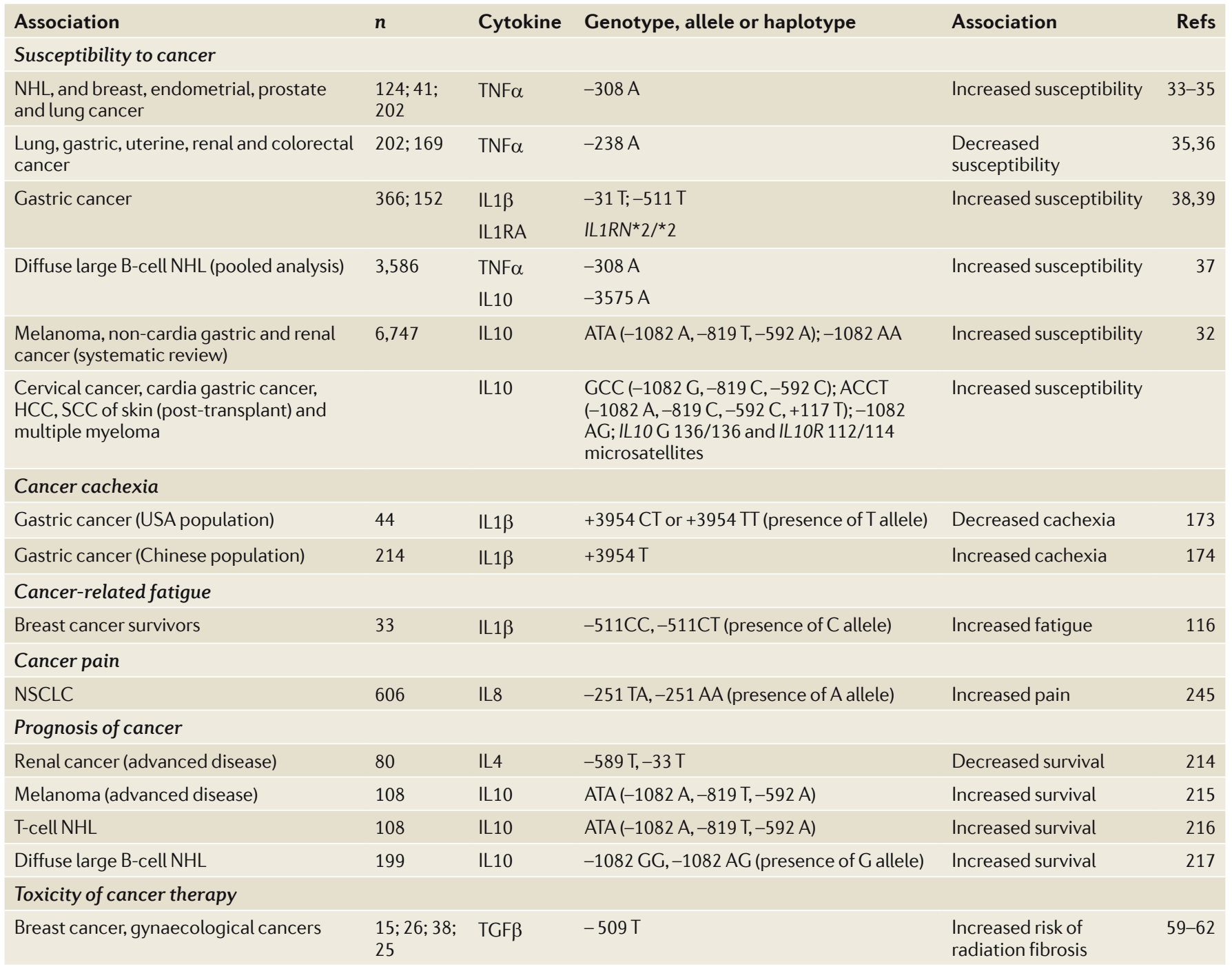

HCC, hepatocellular cancer; IL, interleukin; IL1RA, IL1 receptor antagonist; NHL, non-Hodgkin lymphoma; NSCLC, non-small-cell lung cancer; SCC, squamous cell cancer; TGF $\beta$, transforming growth factor- $\beta$; TNF $\alpha$, tumour necrosis factor- $\alpha$.

fatigue) with or without etanercept, a TNF $\alpha$ decoy receptor, patients had significantly less fatigue and could receive higher doses of docetaxel than those who received docetaxel alone ${ }^{129}$. In a prospective study of patients with Castleman disease, which is a lymphoproliferative disorder characterized by increased production of IL6, administration of a monoclonal antibody against IL6R was strongly associated with reduced fatigue $^{130}$. Also, in three randomized, placebo-controlled clinical trials of adalimumab, a monoclonal antibody against TNF $\alpha$, patients with uncontrolled rheumatoid arthritis receiving adalimumab in combination with methotrexate or other standard therapy had significantly less fatigue than those receiving methotrexate or standard therapy alone ${ }^{131}$.
Brain imaging studies indirectly support an association between cytokines, chemotherapy and cognitive impairment. In a recent study, treatment of patients with hepatitis $C$ using IFN $\alpha$ was associated with impaired cognitive function, which correlated with higher brain activity than healthy controls in the dorsal part of the anterior cingulated cortex during a task of visuospatial attention, as documented by functional magnetic resonance imaging scans ${ }^{132}$. Functional imaging of the brain has shown similar changes in people with cancer who received chemotherapy. For example, 5-10 years after treatment breast cancer survivors who received chemotherapy had higher activity in the lower frontal gyrus, as revealed by functional positron-emission tomography, than breast cancer survivors who were not treated with chemotherapy ${ }^{133}$.
Cytokines and physical activity. There is strong evidence from randomized, controlled trials that aerobic physical activity is able to reduce cancer fatigue ${ }^{134}$, but the underlying mechanisms are unknown. However, there is emerging data indicating that a physically active lifestyle modulates cytokine production and is associated with anti-inflammatory effects. In people with chronic conditions such as obesity, heart failure and metabolic syndromes, which are characterized by increased circulating pro-inflammatory cytokines and other inflammatory markers, intervention studies of chronic physical activity alone or in combination with diet showed reductions in the levels of circulating IL6 and/or TNF $\alpha$ in some $e^{135-138}$ but not all studies $^{139,140}$. Evidence from studies with healthy humans and animals shows that increased 
levels of circulating IL6, which is released intermittently from skeletal muscle during periods of intense physical activity, has strong anti-inflammatory effects due to inhibition of TNF $\alpha$ production and induction of IL10 and IL1RA production ${ }^{141}$. However, this mechanism cannot explain the beneficial effect of exercise on fatigue in people with cancer, especially advanced cancer where less intensive physical activity is beneficial. Studies in people who did not have cancer showed that exercise reduces expression of TLR4 by peripheral innate immune cells and is associated with blunted TLR signalling and lower production of IL1 $\beta$, IL6 and TNF $\alpha^{142}$. Studies in humans and animals suggest that physical activity is important for the health of the brain and causes structural and functional changes. This may occur either directly by induction of central and peripheral growth factors such as insulin-like growth factor 1 (IGF1), brain-derived neurotrophic factor (BDNF) and vascular endothelial growth factor (VEGF, also known as VEGFA) or indirectly by reducing the activity of proinflammatory cytokines that inhibit signalling by these growth factors ${ }^{143}$. These findings further support the involvement of cytokines in cancer-related fatigue, cognitive impairment and the beneficial effects of physical activity.

Cytokines and stress. Cancer poses numerous physical and psychological stresses. Many cancer patients, during both treatment and long-term follow-up, experience psychological distress including anxiety and depression ${ }^{144}$. In animals, stress can activate pro-inflammatory pathways in the brain by activation of microglial cells ${ }^{145,146}$ (FIG. 2), and these cells respond in a heightened fashion when exposed to LPS, either centrally in the brain ${ }^{147}$ or peripherally ${ }^{148}$. In humans, modulation of the immune system by stress is well-known ${ }^{149}$. Studies of chronic and acute stress in models of human stress showed increased circulating levels of IL6 and TNF $\alpha$ compared with controls ${ }^{150-152}$. In stress-related neuropsychiatric disorders there is evidence of abnormal glucocorticoid signalling ${ }^{153}$, and this may occur in people with cancer. In general, depressed patients have an activated HPA axis, increased levels of cortisol and increased circulating levels of several pro-inflammatory cytokines, which can further stimulate the HPA axis and cortisol production ${ }^{154}$. In people with depression there is evidence of malfunction of cortisol receptors leading to cytokine-induced cortisol resistance, impaired feedback

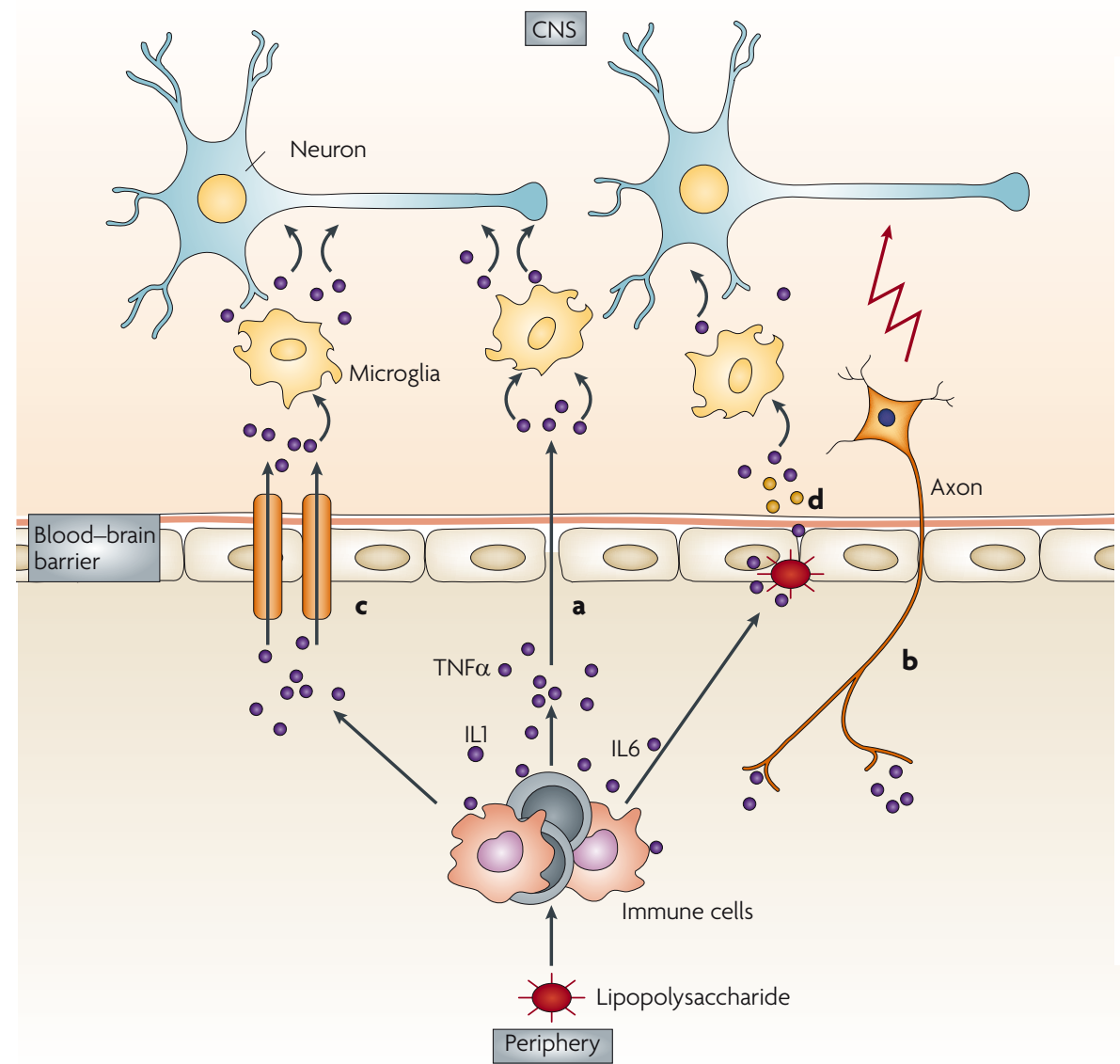

Figure 2 | Pathways of communication between periphery and the central nervous system (CNS). Pro-inflammatory cytokines produced by peripheral immune cells during infection affect the brain by several means. A major pathway of communication involves diffusion of cytokines from the circumventricular organs, which lie outside the blood-brain barrier ${ }^{44,45}$ (a). A second major pathway is across the intact blood-brain barrier and includes activation of sensory afferents of cranial nerves (that is, vagal and glossopharyngeal nerves ${ }^{46,47}$ (b), cytokine transporters at the blood-brain barrier in a saturable transport system ${ }^{48}$ (c), and secretion of immune-active substances (for example, cytokines and prostaglandins) by the cells that constitute the blood-brain barrier ${ }^{49,50}$ (d).

inhibition of the HPA axis and sustained activation of immune cells ${ }^{153,155}$. Depression and psychological distress sensitize and enhance inflammatory responses to subsequent stressful events and to challenge with various antigens ${ }^{149}$. In animal models and in vitro studies, several classes of antidepressants have been shown to reduce pretreatment levels of pro-inflammatory cytokines, such as IFN $\gamma$ and TNF $\alpha$, and to increase the production of anti-inflammatory cytokines, such as IL10. Indeed, antidepressant treatment can lead to normalization of circulating cytokine production in people with depression ${ }^{156}$.

Cancer patients who are clinically depressed have significantly higher levels of circulating IL6 than non-depressed cancer patients or healthy controls ${ }^{157,158}$. In observational studies of breast cancer survivors several years after diagnosis, cancer-related fatigue was strongly associated with depressed mood ${ }^{91}$, supporting a common underlying mechanism. In cancer patients undergoing cytokine therapy with IL2 or IFN $\alpha$, depression was related to decreased levels of circulating tryptophan, a precursor of serotonin, and consequently to decreased availability of serotonin in the brain ${ }^{159}$. Indeed, peripheral pro-inflammatory cytokines can induce sickness behaviour and depression in animals by decreasing the availability of serotonin in the brain ${ }^{160}$.

Despite the association between depression and cancer-related fatigue, therapy with the selective serotonin-reuptake inhibitor paroxetine, which increases synaptic levels of serotonin in the brain, has been found to reduce depression but not fatigue in patients with cancer-receiving chemotherapy ${ }^{161,162}$, 


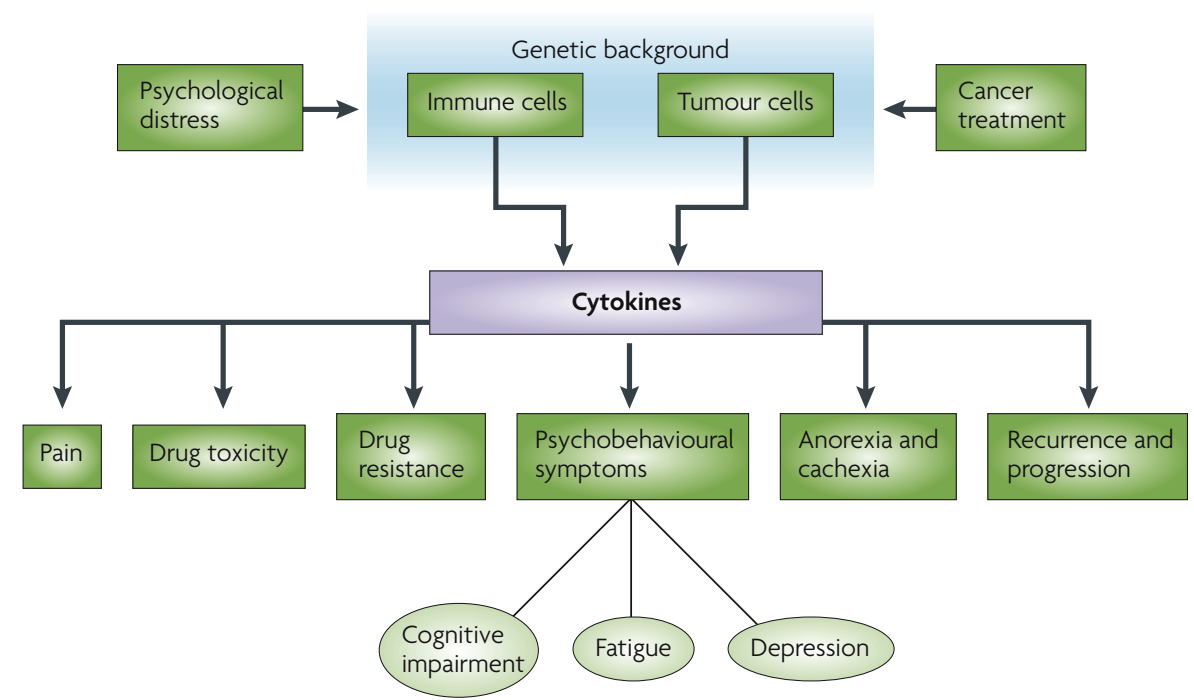

Figure 3 | A conceptual model of cytokines in cancer. Tumour and immune cells are sources of cytokines, which support the growth of cancer and lead to to psychobehavioural symptoms (fatigue, depression, and cognitive impairment), drug toxicity, drug resistance, anorexia and cachexia, pain, and cancer recurrence and progression. Genetic background, cancer treatment and psychological distress may corroborate the production of cytokines. In cancer survivors, hyperactive immune cells might be the major source of cytokines in psychobehavioural symptoms.

suggesting that modulation of serotonin may not be a primary mechanism of fatigue related to cancer. Chronic fatigue might be explained by persistent effects of pro-inflammatory cytokines in the brain and peripheral tissues that are not adequately counterbalanced by anti-inflammatory mechanisms.

Cancer-related fatigue, depression and cognitive impairment usually lead to a sedentary lifestyle, resulting in proinflammatory effects and increased cytokine production that may further sustain these disturbing symptoms ${ }^{142}$. Cytokines are challenging candidate factors in psychobehavioural symptoms ${ }^{163}$ (fatigue, cognitive impairment and depression) (FIG. 3) that need further research.

\section{Cytokines and anorexia and cachexia.}

Anorexia and cachexia occur commonly in patients with some types of cancer such as lung or pancreas, but rarely in those with others such as breast or prostate cancer. Anorexia and cachexia in people with advanced cancer are characterized by breakdown of skeletal muscle and abnormalities in fat and carbohydrate metabolism despite adequate nutritional intake, and are not related simply to burden of disease. Cachectic cancer patients have lower survival rates than patients without significant weight loss ${ }^{164}$.

Support for a role for pro-inflammatory cytokines in the induction of cachexia comes from animal studies, with supporting evidence in humans ${ }^{165,166}$. Increased levels of IL1 in the brain have been associated with anorexia in animals ${ }^{167}$, and pro-inflammatory cytokines may be involved in the development both of anorexia and cachexia and of depression (which frequently coexist) through a common pathway ${ }^{168}$. In particular, TNF $\alpha$ induces proteolysis of skeletal muscle and increased expression of genes that encode enzymes in the ubiquitindependent proteolytic pathway in cancer patients ${ }^{169}$. TNF $\alpha$ also induces uncoupling of mitochondrial respiration and metabolic energy production in animal models ${ }^{170}$. Such molecular changes, including increased activity of muscle ubiquitin proteasome, may be detectable before weight loss ${ }^{171}$, but a small double-blinded, placebo-controlled trial of etanercept did not show benefit in weight, appetite or survival in patients with advanced solid cancers ${ }^{172}$. A possible explanation is the involvement of multiple cytokines in causing the anorexia and cachexia syndrome in cancer patients.

A recent exploratory analysis of the effect of IL $1 \beta$ polymorphisms on cachexia in patients in the United States with advanced gastric cancer suggested a significant association between $I L 1 \beta(-31 \mathrm{C} / \mathrm{T}$ and $\mathrm{T} / \mathrm{T})$ genotypes and diminished appetite - the $\operatorname{IL} 1 \beta(+3,954 \mathrm{C} / \mathrm{T}$ and $\mathrm{T} / \mathrm{T})$ genotypes were associated with greater improvements in weight and survival than the $I L 1 \beta(+3,954$ $\mathrm{C} / \mathrm{C})$ genotype, independent of treatment effect ${ }^{173}$. A similar study in Chinese patients with locally advanced gastric cancer showed a converse association between the $I L 1 \beta$ $(+3,954 \mathrm{~T})$ allele and cachexia ${ }^{174}$ (TABLE 3). These conflicting results, which are commonly seen in candidate gene studies, might also be explained by the different genetic backgrounds of Western and Asian populations, the interplay between different genetic polymorphisms of the same cytokine and interactions between different cytokines.

Cytokines and pain. Cytokine activation and deregulation is recognized in a variety of painful disease states. Neuropathic pain in cancer is common, the major causes being some types of anticancer treatment and the direct infiltration of nerves by cancer cells ${ }^{175}$. In numerous animal studies expression of IL1, IL6 and TNF $\alpha$ is upregulated in peripheral nerves, the spinal cord and in particular regions of the brain after peripheral nerve injury. By contrast, anti-inflammatory cytokines (IL4 and IL10) and neutralizing antibodies against pro-inflammatory cytokines or their receptors promote analgesia $^{176}$. Intrathecal injection of IL1RA or of a vector incorporating IL10 decreased production of pro-inflammatory cytokines in the spinal cord and attenuated neuropathic pain $^{177,178}$. In a study of patients with a variety of pain-associated peripheral neuropathies, levels of circulating pro-inflammatory and anti-inflammatory cytokines were significantly increased and decreased, respectively, compared with patients with painless neuropathies or healthy controls ${ }^{179}$. Shifting the balance from pro- to anti-inflammatory cytokines is a promising approach to management of neuropathic cancer pain.

The release of pro-inflammatory cytokines by peripheral immune cells during inflammation, infection or trauma leads to release of pro-inflammatory cytokines by glia in the CNS; these cytokines are associated with induction and maintenance of pain ${ }^{180}$. Studies in animals and humans show that morphine induces secretion of pro-inflammatory cytokines by glial cells, leading to suppression of acute opioid analgesia, induction of tolerance after repeated opioid administration, development of opioid dependence and the seemingly paradoxical withdrawal-induced enhancement of pain ${ }^{181}$. Preoperative use of pentoxifylline, an inhibitor of cytokine production in immune cells, attenuated release of pro-inflammatory cytokines and reduced morphine consumption after surgery in patients with colorectal cancer ${ }^{182}$. The development of interventions that suppress opioidinduced activity of glial cells might promote better analgesia and enable more effective and safer use of these drugs. 
Cytokines and patient outcome Cytokines, drug toxicity and drug resistance. Most anticancer drugs are metabolized in the liver by cytochrome P450 (CYP) enzymes with the isoenzyme CYP3A4 being most important in this process ${ }^{183}$. Clinical studies have confirmed a relationship between pro-inflammatory cytokines and a systemic inflammatory response with increased levels of CRP, decreased activity of CYP enzymes ${ }^{184,185}$ and increased toxicity of chemotherapy ${ }^{186}$ (FIG. 3). However, the effect of the cancer on the inhibition of CYP enzymes was not studied. Recently, a mechanistic link between IL6 (which is associated with an acute-phase response induced by cancer growth) and impaired hepatic drug metabolism was demonstrated in a transgenic animal model that recreates most aspects of human CYP3A4 regulation ${ }^{187}$.

Although increased levels of pro-inflammatory cytokines can cause impaired metabolism and clearance of anticancer drugs, they may also reduce the anticancer effectiveness of the drugs (FIG. 3). Pro-inflammatory cytokines can lead to activation of NFKB (BOX 1), which enables survival of cancer cells and provides a mechanism by which they might become resistant to chemotherapy and radiotherapy. By contrast, inhibitors of NFKB can sensitize tumour cells to the apoptosis that is induced by chemotherapeutic agents ${ }^{188}$. For example, in human cell lines derived from hormone-refractory prostate cancer, higher activity of NFKB and increased production of IL6 were associated with decreased sensitivity to docetaxel, whereas an NFKB inhibitor decreased production of IL6 and reversed resistance to docetaxel. In the same study, increased circulating levels of IL6 before treatment correlated with less of a decrease in the circulating levels of prostate-specific antigen ${ }^{189}$. Clinical studies in other cancers have confirmed an association between circulating levels of IL6 and resistance to chemotherapy ${ }^{190,191}$.

\section{Prognostic value of cytokines. There is} increasing evidence that the pattern and level of cytokine production is related to cancer prognosis. Genes associated with metastasis can be expressed in cancer and stromal cells in early-stage primary tumours ${ }^{192-194}$, and tumour infiltration by some innate immune cells, such as mast cells and macrophages, has been reported to be detrimental in different human cancers ${ }^{195-198}$. Increased expression of the gene encoding $\underline{\mathrm{CD} 68}$, a macrophage marker, was associated with poor prognosis when used as a part of a 21-gene signature
(Oncotype DX) in breast cancer ${ }^{199}$. A gene expression signature of 17 mainly cytokineencoding genes isolated from non-cancerous liver tissue surrounding hepatocellular carcinoma, indicated that a switch from expression of $\mathrm{T}_{\mathrm{H}} 1$ to $\mathrm{T}_{\mathrm{H}} 2$ cytokines independently predicted tumour metastasis and recurrence ${ }^{200}$. Similarly, a 15-cytokine gene signature in non-cancerous lung tissue with a shift towards $\mathrm{T}_{\mathrm{H}} 2$ cytokines predicted the involvement of regional lymph nodes in patients with adenocarcinoma of the lung, whereas a refined 11-cytokine gene signature from lung tumours and non-cancerous surrounding tissue independently predicted survival in early stage adenocarcinoma of the lung ${ }^{201}$. These findings support the hypotheses that cancer and stromal cells collaborate with surrounding uninvolved tissue in cancer development. Cytokine gene signatures of the non-cancerous surrounding tissue combined with gene signatures of the primary tumour can refine prognostic information for cancer recurrence and provide new insights into the biology of cancer.

The genes that encode IL1, IL6, TNF $\alpha$ and TGF $\beta$ are expressed in metastases from several cancer types, suggesting that common transcriptional programmes are activated during invasion ${ }^{202}$. There is evidence from animal models that risk of metastatic dissemination is dependent on the germline genetic background, which contrasts with the conventional model in which somatic mutations in cancer cells create a subpopulation of cells that disseminate ${ }^{203}$. In patients with early-stage colorectal cancer, high levels of IL6 secretion by peripheral blood mononuclear cells stimulated in vitro by LPS independently predicted for metastatic disease and impaired survival, although some healthy controls were also high producers of IL6 (REF. 204). These results suggest that host factors may have a major role in the progression of cancer.

IL6 is one of the most ubiquitously deregulated cytokines in cancer patient $\mathrm{s}^{205}$ and high levels of circulating IL6 most commonly predicted poor outcome in observational studies $^{23,24,206-208}$ (TABLE 2). Other data suggest that some specific cytokines and their receptors might have a predictive role for outcome in some cancer types ${ }^{20,22,28}$. Stage is an important prognostic factor in every cancer type and in observational studies there is a consistent trend of higher levels of circulating cytokines in more advanced stages of various cancers than in early stages $22,24,27,206,209-211$ (TABLE 2), which further supports an association with outcome of cancer.

Genetic polymorphisms of cytokines might also affect outcome (TABLE 3). In a study of patients with advanced renal cancer, the presence of the IL4 (-589 T, -33 T) haplotype, which is associated with increased expression of this $\mathrm{T}_{\mathrm{H}} 2$ cytokine ${ }^{212,213}$, was an independent prognostic factor for lower survival than that of patients that were homozygous for IL4 (-589 C, $-33 \mathrm{C})^{214}$. However, the same IL4 haplotype ( $-589 \mathrm{~T}$, $-33 \mathrm{~T}$ ) decreased susceptibility for the development of renal cancer ${ }^{214}$. Similarly, the ATA (-1082 A, -819 T, -592 A) haplotype of IL10, which is associated with low production of IL10, independently predicted increased survival in patients with advanced melanoma (but also increased susceptibility for the development of melanoma $)^{215}$ and T-cell non-Hodgkin lymphoma ${ }^{216}$. By contrast, the IL10 (-1082 G) allele, which results in increased secretion of IL10, independently predicted improved survival of patients with diffuse large B-cell lymphoma ${ }^{217}$. Thus, cytokines may have various roles in different stages of cancer and in different cancer types.

Diet, exercise and cytokine levels. Increasing evidence from observational studies indicates that better lifestyle, including moderately intense physical activity ${ }^{218-221}$ and lower fat intake $^{218,222}$, results in improved survival after treatment of patients with early breast and colon cancer. In women with breast cancer, beneficial effects of better lifestyle seem to be stronger in oestrogen receptor (ER)-positive disease $\mathrm{e}^{218-220}$. By contrast, in the Women's Intervention Nutrition Study, a large randomized trial that investigated lifestyle intervention with reduced dietary fat intake, there was a decreased probability of breast cancer recurrence, especially in women with ER-negative breast cancers ${ }^{223}$, indicating involvement of mechanisms other than changes in female sex hormones. In the Million Women Study, higher body mass index was associated with an increased risk for 10 of 17 different cancers and the patterns for cancer mortality were broadly similar to those for cancer incidence ${ }^{224}$. The antiinflammatory effect of physical activity, and the attenuation of inflammation that results from lower fat content in the body, could explain the better outcome of cancer in these studies. A physically active lifestyle leads to reduced TLR4 signalling and decreased production of pro-inflammatory cytokines in non-cancer populations ${ }^{142,225}$ and has been reported to increase cytotoxic activity of $\mathrm{NK}$ cells in breast cancer survivors ${ }^{226}$. White adipose tissue is a source of various cytokines (that is, adipokines) with predominantly pro-inflammatory activity ${ }^{227}$. The increased production of cytokines by adipocytes and 
macrophages that infiltrate adipose tissue is reduced by physical activity and by a hypocalorific diet ${ }^{228}$. The effect of physical activity and other lifestyle interventions on cancer outcome might depend on genetically predetermined ability to produce cytokines and other mediators, such that only a subset of patients with cancer might benefit from such activity.

\section{Concluding remarks}

Pro-inflammatory cytokines are involved in the development and progression of cancer and are also associated with fatigue, depression, cognitive impairment, cachexia and anorexia, and pain, which affect quality of life. Sustained production of some cytokines may also be associated with cancer recurrence and progression. Strategies to inhibit the effects of such cytokines might therefore have a profound effect on quality of life and survival. Given the pleiotropic and redundant nature of cytokines, a successful approach might not involve inhibition of one particular cytokine but rather aim to shift the balance between pro- and anti-inflammatory cytokines. Increasing evidence suggests that, with its anti-inflammatory effects, physical activity might be an important part of treatment with the goals of prevention of fatigue and even prevention of cancer recurrence and death. There is a signal from candidate gene studies that polymorphisms in cytokine genes influence the susceptibility and course of cancer, and the symptoms related to cancer and its treatment.

Bostjan Seruga and lan F. Tannock are at the Division of Medical Oncology, Princess Margaret Hospital, Haibo Zhang is at the Departments of Anaesthesiology and Critical Care Medicine, St. Michael's Hospital, and

Lori J. Bernstein is at the Department of Psychosocial Oncology and Palliative Care, Princess Margaret Hospital, University of Toronto, Toronto, Canada. Correspondence to I.F.T. e-mail:ian.tannock@uhn.on.ca doi: $10.1038 / \mathrm{nrc} 2507$ Published online 10 October 2008

1. Borish, L. C. \& Steinke, J. W. 2. Cytokines and chemokines. J. Allergy Clin. Immunol. 111, S460-S475 (2003).

2. Steinke, J. W. \& Borish, L. 3. Cytokines and chemokines. J. Allergy Clin. Immunol. 117, S441-S445 (2006).

3. Elenkov, I. J. Neurohormonal-cytokine interactions: Implications for inflammation, common human diseases and well-being. Neurochem. Int. 52, 40-51 (2008).

4. Pavlov, V. A. \& Tracey, K. J. The cholinergic antiinflammatory pathway. Brain Behav. Immun. 19, 493-499 (2005)

5. Rhen, T. \& Cidlowski, J. A. Antiinflammatory action of glucocorticoids - new mechanisms for old drugs. N. Engl. J. Med. 353, 1711-1723 (2005).

6. Serhan, C. N. et al. Resolution of inflammation: state of the art, definitions and terms. FASEB J. 21 325-332 (2007)

7. Coussens, L. M. \& Werb, Z. Inflammation and cancer. Nature 420, 860-867 (2002).
8. Denardo, D. G. \& Coussens, L. M. Inflammation and breast cancer. Balancing immune response: crosstalk between adaptive and innate immune cells during breast cancer progression. Breast Cancer Res. 9, 212 (2007).

9. Prehn, R. T. The immune reaction as a stimulator of tumor growth. Science 176, 170-171 (1972).

10. Balkwill, F., Charles, K. A. \& Mantovani, A. Smoldering and polarized inflammation in the initiation and promotion of malignant disease. Cancer Cell 7 , 211-217 (2005).

11. de Visser, K. E., Eichten, A. \& Coussens, L. M Paradoxical roles of the immune system during cancer development. Nature Rev. Cancer 6, 24-37 (2006).

12. Mantovani, A. Cancer: inflammation by remote control. Nature 435, 752-753 (2005).

13. Balkwill, F. Cancer and the chemokine network. Nature Rev. Cancer 4, 540-550 (2004).

14. Mantovani, A., Sozzani, S., Locati, M., Allavena, P. \& Sica, A. Macrophage polarization: tumor-associated macrophages as a paradigm for polarized M2 mononuclear phagocytes. Trends Immunol. 23, 549-555 (2002).

15. Balkwill, F. \& Mantovani, A. Inflammation and cancer: back to Virchow? Lancet 357, 539-545 (2001).

16. Zou, W. Immunosuppressive networks in the tumour environment and their therapeutic relevance. Nature Rev. Cancer 5, 263-274 (2005).

17. Finke, J., Ferrone, S., Frey, A., Mufson, A. \& Ochoa, A. Where have all the T cells gone? Mechanisms of immune evasion by tumors. Immunol. Today $\mathbf{2 0}$ 158-160 (1999)

18. Tan, T. T. \& Coussens, L. M. Humoral immunity, inflammation and cancer. Curr. Opin. Immunol. 19 209-216 (2007)

19. Ruka, W., Rutkowski, P., Kaminska, J., Rysinska, A. ¿ Steffen, J. Alterations of routine blood tests in adult patients with soft tissue sarcomas: relationships to cytokine serum levels and prognostic significance. Ann Oncol. 12, 1423-1432 (2001).

20. Rutkowski, P., Kaminska, J., Kowalska, M., Ruka, W. \& Steffen, J. Cytokine and cytokine receptor serum levels in adult bone sarcoma patients: correlations with local tumor extent and prognosis. J. Surg. Oncol. 84 151-159 (2003).

21. Jiang, X. P., Yang, D. C., Elliott, R. L. \& Head, J. F. Reduction in serum IL- 6 after vacination of breast cancer patients with tumour-associated antigens is related to estrogen receptor status. Cytokine 12, 458-465 (2000)

22. Benoy, I. H. et al. Increased serum interleukin-8 in patients with early and metastatic breast cancer correlates with early dissemination and survival. Clin. Cancer Res. 10, 7157-7162 (2004).

23. Ebrahimi, B., Tucker, S. L., Li, D., Abbruzzese, J. L. \& Kurzrock, R. Cytokines in pancreatic carcinoma: correlation with phenotypic characteristics and prognosis. Cancer 101, 2727-2736 (2004).

24. Liao, W. C. et al. Serum interleukin-6 level but not genotype predicts survival after resection in stages I and III gastric carcinoma. Clin. Cancer Res. 14, 428-434 (2008)

25. Ramsey, S., Lamb, G. W., Aitchison, M. \& McMillan, D. C. The longitudinal relationship between circulating concentrations of C-reactive protein, interleukin- 6 and interleukin-10 in patients undergoing resection for renal cancer. $\mathrm{Br}$. J. Cancer 95, 1076-1080 (2006)

26. Hoffmann, T. K. et al. Aberrant cytokine expression in serum of patients with adenoid cystic carcinoma and squamous cell carcinoma of the head and neck. Head Neck 29, 472-478 (2007).

27. Jebreel, A. et al. Investigation of interleukin 10, 12 and 18 levels in patients with head and neck cancer J. Laryngol. Otol. 121, 246-252 (2007).

28. Tsimberidou, A. M. et al. The prognostic significance of cytokine levels in newly diagnosed acute myeloid leukemia and high-risk myelodysplastic syndromes. Cancer 113, 1605-1613 (2008).

29. Vardy, J. L. et al. Cytokine levels in patients with colorectal cancer and breast cancer and their relationship to fatigue and cognitive function. J. Clin. Oncol. 25, 9070 (2007).

30. Hinds, D. A. et al. Whole-genome patterns of common DNA variation in three human populations. Science 307, 1072-1079 (2005).

31. Dong, L. M. et al. Genetic susceptibility to cancer: the role of polymorphisms in candidate genes. JAMA 299 2423-2436 (2008)

32. Howell, W. M. \& Rose-Zerilli, M. J. Cytokine gene polymorphisms, cancer susceptibility, and prognosis J. Nutr. 137, 194S-199S (2007).
33. Chouchane, L., Ahmed, S. B., Baccouche, S. \& Remadi, S. Polymorphism in the tumor necrosis factor- $\alpha$ promotor region and in the heat shock protein 70 genes associated with malignant tumors. Cancer 80, 1489-1496 (1997).

34. Sasaki, M. et al. Frequent genotype changes at -308 of the human tumor necrosis factor- $\alpha$ promoter region in human uterine endometrial cancer. Oncol. Rep. 7, 369-373 (2000)

35. Shih, C. M. et al. Association of TNF- $\alpha$ polymorphism with susceptibility to and severity of non-small cell lung cancer. Lung Cancer 52, 15-20 (2006).

36. Jang, W. H. et al. The -238 tumor necrosis factor- $\alpha$ promoter polymorphism is associated with decreased susceptibility to cancers. Cancer Lett. 166, 41-46 (2001).

37. Rothman, N. et al. Genetic variation in TNF and IL10 and risk of non-Hodgkin lymphoma: a report from the InterLymph Consortium. Lancet Oncol. 7, 27-38 (2006).

38. El-Omar, E. M. et al. Interleukin-1 polymorphisms associated with increased risk of gastric cancer Nature 404, 398-402 (2000)

39. Machado, J. C. et al. Interleukin 1B and interleukin $1 \mathrm{RN}$ polymorphisms are associated with increased risk of gastric carcinoma. Gastroenterology 121 823-829 (2001)

40. Kamangar, F., Cheng, C., Abnet, C. C. \& Rabkin, C. S. Interleukin-1B polymorphisms and gastric cancer risk - a meta-analysis. Cancer Epidemiol. Biomarkers Prev. 15, 1920-1928 (2006)

41. Balasubramanian, S. P. et al. Interleukin gene polymorphisms and breast cancer: a case control study and systematic literature review. BMC Cancer 6 188 (2006).

42. Chanock, S. J. et al. Replicating genotype-phenotype associations. Nature 447, 655-660 (2007).

43. Mrak, R. E. \& Griffin, W. S. Glia and their cytokines in progression of neurodegeneration. Neurobiol. Aging 26, 349-354 (2005)

44. Quan, N., Whiteside, M. \& Herkenham, M. Time course and localization patterns of interleukin- $1 \beta$ messenger RNA expression in brain and pituitary after peripheral administration of lipopolysaccharide. Neuroscience 83, 281-293 (1998).

45. Vitkovic, L. et al. Cytokine signals propagate through the brain. Mol. Psychiatry 5, 604-615 (2000)

46. Bluthe, R. M. et al. Lipopolysaccharide induces sickness behaviour in rats by a vagal mediated mechanism. C. R. Acad. Sci. III 317, 499-503 (1994)

47. Romeo, H. E., Tio, D. L., Rahman, S. U., Chiappelli, F. \& Taylor, A. N. The glossopharyngeal nerve as a novel pathway in immune-to-brain communication: relevance to neuroimmune surveillance of the oral cavity. J. Neuroimmunol. 115, 91-100 (2001).

48. Banks, W. A. The blood-brain barrier in psychoneuroimmunology. Neurol. Clin. 24, 413-419 (2006).

49. Konsman, J. P., Vigues, S., Mackerlova, L., Bristow, A $\&$ Blomqvist, A. Rat brain vascular distribution of interleukin-1 type-1 receptor immunoreactivity: relationship to patterns of inducible cyclooxygenase expression by peripheral inflammatory stimuli. J. Comp. Neurol. 472, 113-129 (2004).

50. Schiltz, J. C. \& Sawchenko, P. E. Distinct brain vascular cell types manifest inducible cyclooxygenase expression as a function of the strength and nature of immune insults. J. Neurosci. 22, 5606-5618 (2002).

51. Dantzer, R. Cytokine-induced sickness behaviour: a neuroimmune response to activation of innate immunity. Eur. J. Pharmacol. 500, 399-411 (2004).

52. Trask, P. C., Esper, P., Riba, M. \& Redman, B. Psychiatric side effects of interferon therapy: prevalence, proposed mechanisms, and future directions. J. Clin. Oncol. 18, 2316-2326 (2000).

53. Scheibel, R. S., Valentine, A. D., O’Brien, S. \& Meyers, C. A. Cognitive dysfunction and depression during treatment with interferon- $\alpha$ and chemotherapy. J. Neuropsychiatry Clin. Neurosci. 16, 185-191 (2004).

54. Capuron, L., Ravaud, A. \& Dantzer, R. Timing and specificity of the cognitive changes induced by interleukin- 2 and interferon- $\alpha$ treatments in cancer patients. Psychosom. Med. 63, 376-386 (2001).

55. Muller, K. \& Meineke, V. Radiation-induced alterations in cytokine production by skin cells. Exp. Hematol. 35 , 96-104 (2007).

56. Martin, M., Lefaix, J. \& Delanian, S. TGF- $\beta 1$ and radiation fibrosis: a master switch and a specific therapeutic target? Int. J. Radiat. Oncol. Biol. Phys. 47, 277-290 (2000). 
57. Madani, I. et al. Predicting risk of radiation-induced lung injury. J. Thorac. Oncol. 2, 864-874 (2007).

58. Grainger, D. J. et al. Genetic control of the circulating concentration of transforming growth factor type $\beta 1$. Hum. Mol. Genet. 8, 93-97 (1999).

59. Quarmby, S. et al. Association of transforming growth factor $\beta-1$ single nucleotide polymorphisms with radiation-induced damage to normal tissues in breast cancer patients. Int. J. Radiat. Biol. 79, 137-143 (2003).

60. Andreassen, C. N. et al. TGFB1 polymorphisms are associated with risk of late normal tissue complications in the breast after radiotherapy for early breast cancer. Radiother. Oncol. 75, 18-21 (2005).

61. Giotopoulos, G. et al. The late radiotherapy normal tissue injury phenotypes of telangiectasia, fibrosis and atrophy in breast cancer patients have distinct genotype-dependent causes. $\mathrm{Br}$. J. Cancer $\mathbf{9 6}$, 1001-1007 (2007)

62. De Ruyck, K. et al. TGF $\beta 1$ polymorphisms and late clinical radiosensitivity in patients treated for gynecologic tumors. Int. J. Radiat. Oncol. Biol. Phys. 65, 1240-1248 (2006)

63. Demaria, S. et al. Ionizing radiation inhibition of distant untreated tumors (abscopal effect) is immune mediated. Int. J. Radiat. Oncol. Biol. Phys. 58 862-870 (2004)

64. Reits, E. A. et al. Radiation modulates the peptide repertoire, enhances $\mathrm{MHC}$ class I expression, and induces successful antitumor immunotherapy. J. Exp. Med. 203, 1259-1271 (2006).

65. Zitvogel, L., Apetoh, L., Ghiringhelli, F. \& Kroemer, G. Immunological aspects of cancer chemotherapy. Nature Rev. Immunol. 8, 59-73 (2008)

66. Bogdan, C. \& Ding, A. Taxol, a microtubule-stabilizing antineoplastic agent, induces expression of tumor necrosis factor $\alpha$ and interleukin- 1 in macrophages. J. Leukoc. Biol. 52, 119-121 (1992)

67. Ding, A. H., Porteu, F., Sanchez, E. \& Nathan, C. F. Shared actions of endotoxin and taxol on TNF receptors and TNF release. Science 248, 370-372 (1990).

68. Byrd-Leifer, C. A., Block, E. F., Takeda, K., Akira, S. \& Ding, A. The role of MyD88 and TLR4 in the LPS mimetic activity of Taxol. Eur. J. Immunol. 31 , 2448-2457 (2001).

69. Collins, T. S., Lee, L. F. \& Ting, J. P. Paclitaxel up-regulates interleukin-8 synthesis in human lung carcinoma through an NF-kB- and AP-1-dependent mechanism. Cancer Immunol. Immunother. 49, 78-84 (2000).

70. Tsavaris, N., Kosmas, C., Vadiaka, M., Kanelopoulos, P. $\&$ Boulamatsis, D. Immune changes in patients with advanced breast cancer undergoing chemotherapy with taxanes. Br. J. Cancer 87, 21-27 (2002).

71. Pusztai, L. et al. Changes in plasma levels of inflammatory cytokines in response to paclitaxel chemotherapy. Cytokine 25, 94-102 (2004)

72. Wood, L. J. et al. The cancer chemotherapy drug etoposide (VP-16) induces proinflammatory cytokine production and sickness behavior-like symptoms in a mouse model of cancer chemotherapy-related symptoms. Biol. Res. Nurs. 8, 157-169 (2006).

73. Plate, J. M., Plate, A. E., Shott, S., Bograd, S. \& Harris, J. E. Effect of gemcitabine on immune cells in subjects with adenocarcinoma of the pancreas. Cancer Immunol. Immunother. 54, 915-925 (2005).

74. Ramesh, G. \& Reeves, W. B. TNF- $\alpha$ mediates chemokine and cytokine expression and renal injury in cisplatin nephrotoxicity. J. Clin. Invest. 110, 835-842 (2002).

75. Ramesh, G. \& Reeves, W. B. TNFR2-mediated apoptosis and necrosis in cisplatin-induced acute renal failure. Am. J. Physiol. Renal Physiol. 285 F610-F618 (2003).

76. Zhang, B., Ramesh, G., Norbury, C. C. \& Reeves, W. B. Cisplatin-induced nephrotoxicity is mediated by tumor necrosis factor- $\alpha$ produced by renal parenchymal cells. Kidney Int. 72, 37-44 (2007)

77. Sleijfer, S. Bleomycin-induced pneumonitis. Chest $\mathbf{1 2 0}$, 617-624 (2001)

78. Tabata, C. et al. Thalidomide prevents bleomycin induced pulmonary fibrosis in mice. J. Immunol. 179 708-714 (2007)

79. Sime, P. J. \& O'Reilly, K. M. Fibrosis of the lung and other tissues: new concepts in pathogenesis and treatment. Clin. Immunol. 99, 308-319 (2001).

80. Miyazaki, Y. et al. Expression of a tumor necrosis factor-alpha transgene in murine lung causes lymphocytic and fibrosing alveolitis. A mouse model of progressive pulmonary fibrosis. J. Clin. Invest. 96 250-259 (1995).
81. Burstein, H. J. Aromatase inhibitor-associated arthralgia syndrome. Breast 16, 223-234 (2007).

82. Marhhom, E. \& Cohen, I. Fertility preservation options for women with malignancies. Obstet. Gynecol. Surv. 62, 58-72 (2007).

83. Nalbandian, G. \& Kovats, S. Understanding sex biases in immunity: effects of estrogen on the differentiation and function of antigen-presenting cells. Immunol. Res. 31, 91-106 (2005)

84. Carlsten, H. Immune responses and bone loss: the estrogen connection. Immunol. Rev. 208, 194-206 (2005)

85. Weitzmann, M. N. \& Pacifici, R. The role of T lymphocytes in bone metabolism. Immunol. Rev. 208 , 154-168 (2005)

86. Lawrence, D. P., Kupelnick, B., Miller, K., Devine, D. \& Lau, J. Evidence report on the occurrence, assessment, and treatment of fatigue in cancer patients. J. Natl Cancer Inst. Monogr., 40-50 (2004).

87. Ahles, T. A. \& Saykin, A. J. Candidate mechanisms for chemotherapy-induced cognitive changes. Nature Rev. Cancer 7, 192-201 (2007).

88. Hermelink, K. et al. Cognitive function during neoadjuvant chemotherapy for breast cancer: results of a prospective, multicenter, longitudinal study. Cancer 109, 1905-1913 (2007).

89. Vardy, J. \& Tannock, I. Cognitive function after chemotherapy in adults with solid tumours. Crit. Rev. Oncol. Hematol. 63, 183-202 (2007).

90. Ahles, T. A. et al. Neuropsychologic impact of standard-dose systemic chemotherapy in long-term survivors of breast cancer and lymphoma. J. Clin. Oncol. 20, 485-493 (2002).

91. Bower, J. E. et al. Fatigue in long-term breast carcinoma survivors: a longitudinal investigation. Cancer 106, 751-758 (2006).

92. van Dam, A. M., Brouns, M., Louisse, S. \& Berkenbosch, F. Appearance of interleukin-1 in macrophages and in ramified microglia in the brain of endotoxin-treated rats: a pathway for the induction of non-specific symptoms of sickness? Brain Res. $\mathbf{5 8 8}$, 291-296 (1992)

93. Gatti, S. \& Bartfai, T. Induction of tumor necrosis factor- $\alpha$ mRNA in the brain after peripheral endotoxin treatment: comparison with interleukin- 1 family and interleukin-6. Brain Res. 624, 291-294 (1993).

94. Laye, S., Parnet, P., Goujon, E. \& Dantzer, R. Peripheral administration of lipopolysaccharide induces the expression of cytokine transcripts in the brain and pituitary of mice. Brain Res. Mol. Brain Res. 27, 157-162 (1994).

95. Quan, N., Stern, E. L., Whiteside, M. B. \& Herkenham, M. Induction of pro-inflammatory cytokine mRNAs in the brain after peripheral injection of subseptic doses of lipopolysaccharide in the rat. J. Neuroimmunol. 93, 72-80 (1999).

96. Gibertini, M., Newton, C., Friedman, H. \& Klein, T. W. Spatial learning impairment in mice infected with Legionella pneumophila or administered exogenous interleukin-1- $\beta$. Brain Behav. Immun. 9, 113-128 (1995)

97. Aubert, A., Vega, C., Dantzer, R. \& Goodall, G Pyrogens specifically disrupt the acquisition of a task involving cognitive processing in the rat. Brain Behav. Immun. 9, 129-148 (1995).

98. Holden, J. M., Overmier, J. B., Cowan, E. T. \& Matthews, L. Effects of lipopolysaccharide on consolidation of partial learning in the Y-maze. Integr. Physiol. Behav. Sci. 39, 334-340 (2004).

99. Gahtan, E. \& Overmier, J. B. Performance more than working memory disrupted by acute systemic inflammation in rats in appetitive tasks. Physiol. Behav. 73, 201-210 (2001).

100. Sparkman, N. L. et al. Interleukin-6 facilitates lipopolysaccharide-induced disruption in working memory and expression of other proinflammatory cytokines in hippocampal neuronal cell layers. J. Neurosci. 26, 10709-10716 (2006)

101. Heyen, J. R., Ye, S., Finck, B. N. \& Johnson, R. W. Interleukin (IL)-10 inhibits IL-6 production in microglia by preventing activation of NF-кB. Brain Res. Mol. Brain Res. 77, 138-147 (2000)

102. Krzyszton, C. P. et al. Exacerbated fatigue and motor deficits in interleukin-10 deficient mice after peripheral immune stimulation. Am. J. Physiol. Regul. Integr. Comp. Physiol. 23 Jul 2008 (doi:10.1152/ ajpregu.90303.2008)

103. Krabbe, K. S. et al. Low-dose endotoxemia and human neuropsychological functions. Brain Behav. Immun. 19, 453-460 (2005).
104. Krabbe, K. S., Pedersen, M. \& Bruunsgaard, H. Inflammatory mediators in the elderly. Exp. Gerontol. 39, 687-699 (2004)

105. Goshen, I. et al. A dual role for interleukin-1 in hippocampal-dependent memory processes. Psychoneuroendocrinology 32, 1106-1115 (2007).

106. Zipp, F. \& Aktas, O. The brain as a target of inflammation: common pathways link inflammatory and neurodegenerative diseases. Trends Neurosci. 29 518-527 (2006)

107. Mohankumar, P. S., Thyagarajan, S. \& Quadri, S. K. Interleukin-1 stimulates the release of dopamine and dihydroxyphenylacetic acid from the hypothalamus in vivo. Life Sci. 48, 925-930 (1991).

108. Shintani, F. et al. Interleukin-1 $\beta$ augments release of norepinephrine, dopamine, and serotonin in the rat anterior hypothalamus. J. Neurosci. 13, 3574-3581 (1993).

109. Meyers, C. A., Albitar, M. \& Estey, E. Cognitive impairment, fatigue, and cytokine levels in patients with acute myelogenous leukemia or myelodysplastic syndrome. Cancer 104, 788-793 (2005).

110. Schubert, C., Hong, S., Natarajan, L., Mills, P. J. \& Dimsdale, J. E. The association between fatigue and inflammatory marker levels in cancer patients: a quantitative review. Brain Behav. Immun. 21, 413-427 (2007)

111. Bower, J. E. Cancer-related fatigue: links with inflammation in cancer patients and survivors. Brain Behav. Immun. 21, 863-871 (2007).

112. Collado-Hidalgo, A., Bower, J. E., Ganz, P. A. Cole, S. W. \& Irwin, M. R. Inflammatory biomarkers for persistent fatigue in breast cancer survivors. Clin. Cancer Res. 12, 2759-2766 (2006).

113. Bower, J. E. et al. Diurnal cortisol rhythm and fatigue in breast cancer survivors. Psychoneuroendocrinology 30, 92-100 (2005)

114. Bower, J. E., Ganz, P. A. \& Aziz, N. Altered cortisol response to psychologic stress in breast cancer survivors with persistent fatigue. Psychosom. Med. 67, 277-280 (2005)

115. Bower, J. E. et al. Inflammatory responses to psychological stress in fatigued breast cancer survivors: relationship to glucocorticoids. Brain Behav. Immun. 21, 251-258 (2007).

116. Collado-Hidalgo, A., Bower, J. E., Ganz, P. A., Irwin, M. R. \& Cole, S. W. Cytokine gene polymorphisms and fatigue in breast cancer survivors: Early findings. Brain Behav. Immun. 9 Jul 2008 (doi:10.1016/j. bbi.2008.05.009)

117. Smyth, J. M. et al. Individual differences in the diurnal cycle of cortisol. Psychoneuroendocrinology 22, 89-105 (1997).

118. Stone, A. A. et al. Individual differences in the diurnal cycle of salivary free cortisol: a replication of flattened cycles for some individuals. Psychoneuroendocrinology 26, 295-306 (2001)

119. Groenvold, M. et al. Psychological distress and fatigue predicted recurrence and survival in primary breast cancer patients. Breast Cancer Res. Treat. 105 209-219 (2007)

120. Coates, A. S. et al. Quality-of-life scores predict outcome in metastatic but not early breast cancer. International Breast Cancer Study Group. J. Clin. Oncol. 18, 3768-3774 (2000).

121. Goodwin, P. J. et al. Health-related quality of life and psychosocial status in breast cancer prognosis: analysis of multiple variables. J. Clin. Oncol. 22, 4184-4192 (2004).

122. Steel, J. L., Geller, D. A., Gamblin, T. C., Olek, M. C. \& Carr, B. I. Depression, immunity, and survival in patients with hepatobiliary carcinoma. J. Clin. Oncol. 25, 2397-2405 (2007)

123. Onitilo, A. A., Nietert, P. J. \& Egede, L. E. Effect of depression on all-cause mortality in adults with cancer and differential effects by cancer site. Gen. Hosp. Psychiatry 28, 396-402 (2006).

124. Spiegel, D. \& Giese-Davis, J. Depression and cancer: mechanisms and disease progression. Biol. Psychiatry 54, 269-282 (2003)

125. Irwin, M. R. Depression and risk of cancer progression: an elusive link. J. Clin. Oncol. 25 , 2343-2344 (2007).

126. Andersen, B. L. et al. Stress and immune responses after surgical treatment for regional breast cancer. J. Natl Cancer Inst. 90, 30-36 (1998).

127. Lutgendorf, S. K. et al. Social support psychological distress, and natural killer cell activity in ovarian cancer. J. Clin. Oncol. 23, 7105-7113 (2005). 
128. Sephton, S. E., Sapolsky, R. M., Kraemer, H. C. ¿ Spiegel, D. Diurnal cortisol rhythm as a predictor of breast cancer survival. J. NatI Cancer Inst. 92 , 994-1000 (2000)

129. Monk, J. P. et al. Assessment of tumor necrosis factor $\alpha$ blockade as an intervention to improve tolerability of dose-intensive chemotherapy in cancer patients. J. Clin. Oncol. 24, 1852-1859 (2006).

130. Nishimoto, N. et al. Humanized anti-interleukin-6 receptor antibody treatment of multicentric Castleman disease Blood 106, 2627-2632 (2005).

131. Yount, S. et al. Adalimumab plus methotrexate or standard therapy is more effective than methotrexate or standard therapies alone in the treatment of fatigue in patients with active, inadequately treated rheumatoid arthritis. Clin. Exp. Rheumatol. 25 838-846 (2007)

132. Capuron, L. et al. Anterior cingulate activation and error processing during interferon- $\alpha$ treatment. Biol. Psychiatry 58, 190-196 (2005).

133. Silverman, D. H. et al. Altered frontocortical, cerebellar, and basal ganglia activity in adjuvanttreated breast cancer survivors 5-10 years after chemotherapy. Breast Cancer Res. Treat. 103. 303-311 (2007)

134. Mustian, K. M. et al. Integrative nonpharmacologic behavioral interventions for the management of cancer-related fatigue. Oncologist 12 (Suppl. 1), 52-67 (2007).

135. Nicklas, B. J., You, T. \& Pahor, M. Behavioural treatments for chronic systemic inflammation: effects of dietary weight loss and exercise training. CMAJ 172, 1199-1209 (2005).

136. Goldhammer, E. et al. Exercise training modulates cytokines activity in coronary heart disease patients. Int. J. Cardiol. 100, 93-99 (2005).

137. Adamopoulos, S. et al. Physical training modulates proinflammatory cytokines and the soluble Fas/soluble Fas ligand system in patients with chronic heart failure. J. Am. Coll Cardiol. 39, 653-663 (2002).

138. Conraads, V. M. et al. Combined endurance/resistance training reduces plasma TNF- $\alpha$ receptor levels in patients with chronic heart failure and coronary artery disease. Eur. Heart J. 23, 1854-1860 (2002).

139. Polak, J. et al. Effect of aerobic training on plasma levels and subcutaneous abdominal adipose tissue gene expression of adiponectin, leptin, interleukin 6 , and tumor necrosis factor alpha in obese women. Metabolism 55, 1375-1381 (2006)

140. Oberbach, A. et al. Effect of a 4 week physical training program on plasma concentrations of inflammatory markers in patients with abnormal glucose tolerance. Eur. J. Endocrinol. 154, 577-585 (2006).

141. Petersen, A. M. \& Pedersen, B. K. The ant inflammatory effect of exercise. J. Appl. Physiol. 98 1154-1162 (2005)

142. Flynn, M. G. \& McFarlin, B. K. Toll-like receptor 4 link to the anti-inflammatory effects of exercise? Exerc. Sport Sci. Rev. 34, 176-181 (2006).

143. Cotman, C. W., Berchtold, N. C. \& Christie, L. A Exercise builds brain health: key roles of growth facto cascades and inflammation. Trends Neurosci. 30 464-472 (2007)

144. Zabora, J., BrintzenhofeSzoc, K., Curbow, B. Hooker, C. \& Piantadosi, S. The prevalence of psychological distress by cancer site. Psychooncology 10, 19-28 (2001)

145. Frank, M. G., Baratta, M. V., Sprunger, D. B., Watkins, L. R. \& Maier, S. F. Microglia serve as a neuroimmune substrate for stress-induced potentiation of CNS pro-inflammatory cytokine responses. Brain Behav. Immun. 21, 47-59 (2007)

146. Deak, T. et al. Stress-induced increases in hypothalamic IL-1: a systematic analysis of multiple stressor paradigms. Brain Res. Bull. 64, 541-556 (2005).

147. de Pablos, R. M. et al. Stress increases vulnerability to inflammation in the rat prefrontal cortex. J. Neurosci. 26, 5709-5719 (2006)

148. Johnson, J. D. et al. Prior stressor exposure sensitizes LPS-induced cytokine production. Brain Behav. Immun. 16, 461-476 (2002).

149. Glaser, R. \& Kiecolt-Glaser, J. K. Stress-induced immune dysfunction: implications for health. Nature Rev. Immunol. 5, 243-251 (2005).

150. Kiecolt-Glaser, J. K. et al. Chronic stress and agerelated increases in the proinflammatory cytokine IL-6. Proc. Natl Acad. Sci. USA 100, 9090-9095 (2003).

151. Graham, J. E. et al. Hostility and pain are related to inflammation in older adults. Brain Behav. Immun. 20, 389-400 (2006).
152. Kiecolt-Glaser, J. K. et al. Hostile marital interactions, proinflammatory cytokine production, and wound healing. Arch. Gen. Psychiatry 62, 1377-1384 (2005).

153. Raison, C. L. \& Miller, A. H. When not enough is too much: the role of insufficient glucocorticoid signaling in the pathophysiology of stress-related disorders. Am. J. Psychiatry 160, 1554-1565 (2003).

154. Irwin, M. R. \& Miller, A. H. Depressive disorders and immunity: 20 years of progress and discovery. Brain Behav. Immun. 21, 374-383 (2007).

155. Pace, T. W., Hu, F. \& Miller, A. H. Cytokine-effects on glucocorticoid receptor function: relevance to glucocorticoid resistance and the pathophysiology and treatment of major depression. Brain Behav. Immun. 21, 9-19 (2007).

156. Kenis, G. \& Maes, M. Effects of antidepressants on the production of cytokines. Int J. Neuropsychopharmacol. 5, 401-412 (2002)

157. Musselman, D. L. et al. Higher than normal plasma interleukin-6 concentrations in cancer patients with depression: preliminary findings. Am. J. Psychiatry 158, 1252-1257 (2001).

158. Soygur, H. et al. Interleukin-6 levels and HPA axis activation in breast cancer patients with major depressive disorder. Prog. Neuropsychopharmacol. Biol. Psychiatry 31, 1242-1247 (2007).

159. Capuron, L. et al. Association between decreased serum tryptophan concentrations and depressive symptoms in cancer patients undergoing cytokine therapy. Mol. Psychiatry 7, 468-473 (2002).

160. Dantzer, R., O'Connor, J. C., Freund, G. G. Johnson, R. W. \& Kelley, K. W. From inflammation to sickness and depression: when the immune system subjugates the brain. Nature Rev. Neurosci. 9, 46-56 (2008).

161. Morrow, G. R. et al. Differential effects of paroxetine on fatigue and depression: a randomized, double-blind trial from the University of Rochester Cancer Center Community Clinical Oncology Program. J. Clin. Oncol. 21, 4635-4641 (2003).

162. Roscoe, J. A. et al. Effect of paroxetine hydrochloride (Paxil) on fatigue and depression in breast cancer patients receiving chemotherapy. Breast Cancer Res. Treat. 89, 243-249 (2005)

163. Miller, A. H., Ancoli-Israel, S., Bower, J. E., Capuron, L. \& Irwin, M. R. Neuroendocrine-immune mechanisms of behavioral comorbidities in patients with cancer. J. Clin. Oncol. 26, 971-982 (2008)

164. Tisdale, M. J. Biology of cachexia. J. Natl Cancer Inst. 89, 1763-1773 (1997)

165. Ramos, E. J. et al. Cancer anorexia-cachexia syndrome: cytokines and neuropeptides. Curr. Opin. Clin. Nutr. Metab. Care 7, 427-434 (2004).

166. Argiles, J. M., Busquets, S. \& Lopez-Soriano, F. J. The pivotal role of cytokines in muscle wasting during cancer. Int. J. Biochem. Cell Biol. 37, 2036-2046 (2005).

167. Laviano, A., Meguid, M. M. \& Rossi-Fanelli, F. Cance anorexia: clinical implications, pathogenesis, and therapeutic strategies. Lancet Oncol. 4, 686-694 (2003).

168. Illman, J. et al. Are inflammatory cytokines the common link between cancer-associated cachexia and depression? J. Support. Oncol. 3, 37-50 (2005).

169. Bossola, M. et al. Increased muscle ubiquitin mRNA levels in gastric cancer patients. Am. J. Physiol. Regul. Integr. Comp. Physiol. 280, R1518-R1523 (2001).

170. Busquets, S. et al. Tumour necrosis factor- $\alpha$ uncouples respiration in isolated rat mitochondria. Cytokine $\mathbf{2 2}$ $1-4$ (2003)

171. Bossola, M. et al. Increased muscle proteasome activity correlates with disease severity in gastric cancer patients. Ann. Surg. 237, 384-389 (2003)

172. Jatoi, A. et al. A placebo-controlled double blind trial of etanercept for the cancer anorexia/weight loss syndrome: results from $\mathrm{NOOC} 1$ from the North Central Cancer Treatment Group. Cancer 110, 1396-1403 (2007)

173. Jatoi, A. et al. Interleukin-1 genetic polymorphisms and their relationship to the cancer anorexia/weight loss syndrome in metastatic gastric and gastroesophageal junction adenocarcinoma. J. Support. Oncol. 5, 41-46 (2007).

174. Zhang, D. et al. Association of IL-1 $\beta$ gene polymorphism with cachexia from locally advanced gastric cancer. BMC Cancer 7, 45 (2007).

175. Chang, V. T., Janjan, N., Jain, S. \& Chau, C. Update in cancer pain syndromes. J. Palliat. Med. 9 1414-1434 (2006)

176. Schafers, M. \& Sommer, C. Anticytokine therapy in neuropathic pain management. Expert Rev. Neurother 7, 1613-1627 (2007)
177. Ledeboer, A. et al. Intrathecal interleukin-10 gene therapy attenuates paclitaxel-induced mechanical allodynia and proinflammatory cytokine expression in dorsal root ganglia in rats. Brain Behav. Immun. 21, 686-698 (2007).

178. Milligan, E. D. et al. Controlling neuropathic pain by adeno-associated virus driven production of the antiinflammatory cytokine, interleukin-10. Mol. Pain 1, 9 (2005).

179. Uceyler, N., Rogausch, J. P., Toyka, K. V. \& Sommer, C. Differential expression of cytokines in painful and painless neuropathies. Neurology 69, 42-49 (2007).

180. Watkins, L. R. \& Maier, S. F. The pain of being sick: implications of immune-to-brain communication for understanding pain. Annu. Rev. Psychol. 51, 29-57 (2000).

181. Watkins, L. R. et al. Norman Cousins Lecture. Glia as the "bad guys": implications for improving clinical pain control and the clinical utility of opioids. Brain Behav. Immun. 21, 131-146 (2007).

182. Lu, C. H. et al. Preincisional intravenous pentoxifylline attenuating perioperative cytokine response, reducing morphine consumption, and improving recovery of bowel function in patients undergoing colorectal cancer surgery. Anesth. Analg. 99, 1465-1471 (2004).

183. Kivisto, K. T., Kroemer, H. K. \& Eichelbaum, M. The role of human cytochrome $\mathrm{P} 450$ enzymes in the metabolism of anticancer agents: implications for drug interactions. Br. J. Clin. Pharmacol. 40, 523-530 (1995).

184. Islam, M. et al. Differential effect of IFN $\alpha-2 b$ on the cytochrome $\mathrm{P} 450$ enzyme system: a potential basis of IFN toxicity and its modulation by other drugs. Clin. Cancer Res. 8, 2480-2487 (2002).

185. Rivory, L. P., Slaviero, K. A. \& Clarke, S. J. Hepatic cytochrome P450 3A drug metabolism is reduced in cancer patients who have an acute-phase response. Br. J. Cancer 87, 277-280 (2002).

186. Slaviero, K. A., Clarke, S. J. \& Rivory, L. P. Inflammatory response: an unrecognised source of variability in the pharmacokinetics and pharmacodynamics of cancer chemotherapy. Lancet Oncol. 4, 224-232 (2003).

187. Charles, K. A. et al. Transcriptional repression of hepatic cytochrome P450 3A4 gene in the presence of cancer. Clin. Cancer Res. 12, 7492-7497 (2006).

188. Ravi, R. \& Bedi, A. NF-кB in cancer - a friend turned foe. Drug Resist. Updat. 7, 53-67 (2004).

189. Domingo-Domenech, J. et al. Interleukin 6, a nuclear factor- $\mathrm{kB}$ target, predicts resistance to docetaxel in hormone-independent prostate cancer and nuclear factor-кB inhibition by PS-1145 enhances docetaxel antitumor activity. Clin. Cancer Res. 12, 5578-5586 (2006).

190. De Vita, F. et al. Serum levels of interleukin-6 as a prognostic factor in advanced non-small cell lung cancer. Oncol. Rep 5, 649-652 (1998).

191. Zhang, G. J. \& Adachi, I. Serum interleukin-6 levels correlate to tumor progression and prognosis in metastatic breast carcinoma. Anticancer Res. 19 1427-1432 (1999)

192. van 't Veer, L. J. et al. Gene expression profiling predicts clinical outcome of breast cancer. Nature 415, 530-536 (2002).

193. Ye, Q. H. et al. Predicting hepatitis B virus-positive metastatic hepatocellular carcinomas using gene expression profiling and supervised machine learning. Nature Med. 9, 416-423 (2003)

194. Beer, D. G. et al. Gene-expression profiles predict survival of patients with lung adenocarcinoma. Nature Med. 8, 816-824 (2002).

195. Imada, A., Shijubo, N., Kojima, H. \& Abe, S. Mast cells correlate with angiogenesis and poor outcome in stage lung adenocarcinoma. Eur. Respir. J. 15, 1087-1093 (2000).

196. Ribatti, D. et al. Tumor vascularity and tryptasepositive mast cells correlate with a poor prognosis in melanoma. Eur. J. Clin. Invest. 33, 420-425 (2003).

197. Leek, R. D. et al. Association of macrophage infiltration with angiogenesis and prognosis in invasive breast carcinoma. Cancer Res. 56, 4625-4629 (1996).

198. Hanada, T. et al. Prognostic value of tumor-associated macrophage count in human bladder cancer. Int. J. Urol. 7, 263-269 (2000).

199. Paik, S. et al. A multigene assay to predict recurrence of tamoxifen-treated, node-negative breast cancer. N. Engl. J. Med. 351, 2817-2826 (2004). 
200. Budhu, A. et al. Prediction of venous metastases, recurrence, and prognosis in hepatocellular carcinoma based on a unique immune response signature of the liver microenvironment. Cancer Cell 10, 99-111 (2006).

201. Seike, M. et al. Use of a cytokine gene expression signature in lung adenocarcinoma and the surrounding tissue as a prognostic classifier. J. Nat/ Cancer Inst. 99, 1257-1269 (2007).

202. Loberg, R. D., Bradley, D. A., Tomlins, S. A., Chinnaiyan, A. M. \& Pienta, K. J. The lethal phenotype of cancer: the molecular basis of death due to malignancy. CA Cancer J. Clin. 57, 225-241 (2007).

203. Hunter, K. Host genetics influence tumour metastasis. Nature Rev. Cancer 6, 141-146 (2006).

204. Clinchy, B. et al. Preoperative interleukin-6 production by mononuclear blood cells predicts survival after radical surgery for colorectal carcinoma. Cancer 109 1742-1749 (2007).

205. Hong, D. S., Angelo, L. S. \& Kurzrock, R. Interleukin-6 and its receptor in cancer: implications for Translational Therapeutics. Cancer 110, 1911-1928 (2007).

206. Salgado, R. et al. Circulating interleukin-6 predicts survival in patients with metastatic breast cancer. Int. J. Cancer 103, 642-646 (2003).

207. Negrier, S. et al. Interleukin-6, interleukin-10, and vascular endothelial growth factor in metastatic renal cell carcinoma: prognostic value of interleukin- 6 from the Groupe Francais d'Immunotherapie. J. Clin Oncol. 22, 2371-2378 (2004).

208. Shariat, S. F. et al. External validation of a biomarkerbased preoperative nomogram predicts biochemical recurrence after radical prostatectomy. J. Clin. Oncol. 26, 1526-1531 (2008).

209. Kozlowski, L., Zakrzewska, I., Tokajuk, P. \& Wojtukiewicz, M. Z. Concentration of interleukin- 6 (IL-6), interleukin-8 (IL-8) and interleukin-10 (IL-10) in blood serum of breast cancer patients. Rocz. Akad. Med. Bialymst. 48, 82-84 (2003).

210. Nishimura, R. et al. An analysis of serum interleukin-6 levels to predict benefits of medroxyprogesterone acetate in advanced or recurrent breast cancer Oncology 59, 166-173 (2000).

211. Sparano, A., Lathers, D. M., Achille, N., Petruzzelli, G. J. \& Young, M. R. Modulation of Th 1 and Th2 cytokine profiles and their association with advanced head and neck squamous cell carcinoma. Otolaryngol. Head Neck Surg. 131, 573-576 (2004).

212. Nakashima, H. et al. Association between IL-4 genotype and IL-4 production in the Japanese population. Genes Immun. 3, 107-109 (2002)

213. Vandenbroeck, K. \& Goris, A. Cytokine gene polymorphisms in multifactorial diseases: gateways to novel targets for immunotherapy? Trends Pharmacol. Sci. 24, 284-289 (2003).

214. Kleinrath, T., Gassner, C., Lackner, P., Thurnher, M. \& Ramoner, R. Interleukin-4 promoter polymorphisms: a genetic prognostic factor for survival in metastatic renal cell carcinoma. J. Clin. Oncol. 25, 845-851 (2007).

215. Vuoristo, M. S. The polymorphisms of interleukin-10 gene influence the prognosis of patients with advanced melanoma. Cancer Genet. Cytogenet. 176, 54-57 (2007).

216. Lee, J. J. et al. Interleukin-10 gene polymorphism influences the prognosis of T-cell non-Hodgkin lymphomas. Br. J. Haematol. 137, 329-336 (2007).
217. Lech-Maranda, E. et al. Interleukin-10 gene promoter polymorphisms influence the clinical outcome of diffuse large B-cell lymphoma. Blood 103, 3529-3534 (2004)

218. Pierce, J. P. et al. Greater survival after breast cancer in physically active women with high vegetable-fruit intake regardless of obesity. J. Clin. Oncol. 25 2345-2351 (2007)

219. Holmes, M. D., Chen, W. Y., Feskanich, D., Kroenke, C. H. \& Colditz, G. A. Physical activity and survival after breast cancer diagnosis. JAMA 293 2479-2486 (2005)

220. Irwin, M. L. et al. Influence of pre- and postdiagnosis physical activity on mortality in breast cancer survivors: the health, eating, activity, and lifestyle study. J. Clin. Oncol. 26, 3958-3964 (2008).

221. Meyerhardt, J. A. et al. Physical activity and survival after colorectal cancer diagnosis. J. Clin. Oncol. 24, 3527-3534 (2006)

222. Zhang, S., Folsom, A. R., Sellers, T. A., Kushi, L. H. \& Potter, J. D. Better breast cancer survival for postmenopausal women who are less overweight and eat less fat. The lowa Women's Health Study. Cancer 76, 275-283 (1995).

223. Chlebowski, R. T. et al. Dietary fat reduction and breast cancer outcome: interim efficacy results from the Women's Intervention Nutrition Study. J. Natl Cancer Inst. 98, 1767-1776 (2006).

224. Reeves, G. K. et al. Cancer incidence and mortality in relation to body mass index in the Million Women Study: cohort study. BMJ 335, 1134 (2007).

225. Smith, J. K., Dykes, R., Douglas, J. E., Krishnaswamy, G. \& Berk, S. Long-term exercise and atherogenic activity of blood mononuclear cells in persons at risk of developing ischemic heart disease. JAMA $\mathbf{2 8 1}$, 1722-1727 (1999).

226. Fairey, A. S. et al. Randomized controlled trial of exercise and blood immune function in postmenopausal breast cancer survivors. J. Appl. Physiol. 98, 1534-1540 (2005).

227. Lago, F., Dieguez, C., Gomez-Reino, J. \& Gualillo, O. Adipokines as emerging mediators of immune response and inflammation. Nature Clin. Pract. Rheumatol. 3, 716-724 (2007).

228. Bruun, J. M., Helge, J. W., Richelsen, B. \& Stallknecht, B. Diet and exercise reduce low-grade inflammation and macrophage infiltration in adipose tissue but not in skeletal muscle in severely obese subjects. $A m$. J. Physiol. Endocrinol. Metab. 290, E961-E967 (2006).

229. Tosi, M. F. Innate immune responses to infection J. Allergy Clin. Immunol. 116, 241-249 (2005)

230. Iwasaki, A. \& Medzhitov, R. Toll-like receptor control of the adaptive immune responses. Nature Immunol. 5, 987-995 (2004)

231. Janeway, C. A. Jr \& Medzhitov, R. Innate immune recognition. Annu. Rev. Immunol. 20, 197-216 (2002)

232. Chen, R., Alvero, A. B., Silasi, D. A., Steffensen, K. D. $\&$ Mor, G. Cancers take their Toll - the function and regulation of Toll-like receptors in cancer cells. Oncogene 27, 225-233 (2008).

233. Jego, G., Bataille, R., Geffroy-Luseau, A., Descamps, G. $\&$ Pellat-Deceunynck, C. Pathogen-associated molecular patterns are growth and survival factors for human myeloma cells through Toll-like receptors. Leukemia 20, 1130-1137 (2006).
234. He, W. et al. TLR4 signaling promotes immune escape of human lung cancer cells by inducing immunosuppressive cytokines and apoptosis resistance. Mol. Immunol. 44, 2850-2859 (2007)

235. Kelly, M. G. et al. TLR-4 signaling promotes tumor growth and paclitaxel chemoresistance in ovarian cancer. Cancer Res. 66, 3859-3868 (2006).

236. Allavena, P., Sica, A., Solinas, G., Porta, C. \& Mantovani, A. The inflammatory micro-environment in tumor progression: The role of tumor-associated macrophages. Crit. Rev. Oncol. Hematol. (2007).

237. Garcia, K. C., Teyton, L. \& Wilson, I. A. Structural basis of T cell recognition. Annu. Rev. Immunol. 17, 369-397 (1999).

238. Gutcher, I. \& Becher, B. APC-derived cytokines and $T$ cell polarization in autoimmune inflammation. J. Clin. Invest. 117, 1119-1127 (2007).

239. Mosmann, T. R. \& Sad, S. The expanding universe of T-cell subsets: Th1, Th2 and more. Immunol. Today 17, 138-146 (1996)

240. Coffman, R. L. Origins of the $\mathrm{T}_{\mathrm{H}} 1-\mathrm{T}_{\mathrm{H}} 2$ model: a personal perspective. Nature Immunol. 7, 539-541 (2006).

241. Park, H. et al. A distinct lineage of CD4 T cells regulates tissue inflammation by producing interleukin 17. Nature Immunol. 6, 1133-114 (2005).

242. Wang, H. Y. \& Wang, R. F. Regulatory T cells and cancer. Curr. Opin. Immunol. 19, 217-223 (2007).

243. Chen, Z. et al. Expression of proinflammatory and proangiogenic cytokines in patients with head and neck cancer. Clin. Cancer Res. 5, 1369-1379 (1999).

244. Casasnovas, R. O. et al. Plasma cytokine and soluble receptor signature predicts outcome of patients with classical Hodgkin's lymphoma: a study from the Groupe d'Etude des Lymphomes de l'Adulte. J. Clin. Oncol. 25, 1732-1740 (2007).

245. Reyes-Gibby, C. C. et al. Cytokine genes and pain severity in lung cancer: exploring the influence of TNF- $\alpha-308$ G/A IL6-174G/C and IL8-251T/A. Cancer Epidemiol. Biomarkers Prev. 16, 2745-2751 (2007).

DATABASES

National Cancer Institute: http://www.cancer.gov/ breast cancer $\mid$ colorectal cancer $\mid$ etanercept $\mid$ Hodgkin lymphoma | kidney cancer | lung carcinoma | ovarian cancer | pancreatic cancer | prostate cancer

National Cancer Institute Drug Dictionary: http://www. cancer.gov/drugdictionary/

bleomycin | cisplatin | docetaxel | etoposide | gemcitabine | methotrexate | paclitaxel| testicular tumours UniProtKB: http://www.uniprot.org

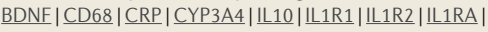
IL2 | IL6 | IL6R | TGF $\beta 1$ | TLR4 | TNF $\alpha$ |VEGFA

FURTHER INFORMATION

I. F. Tannock's homepage: http://uhnresearch.ca/ researchers/profile.php?lookup $=5941$

Cytokine gene polymorphism in human disease: http:// www.nanea.dk/cytokinesnps

ALL LINKS ARE ACTIVE IN THE ONLINE PDF 